\title{
LOS PROBLEMAS DE INTERPRETACION Y APLICACION DE LAS MATERIAS EN LAS REGLAS DE DISTRIBUCION DE COMPETENCIA
}

\author{
POR \\ Gonzalo SAMANIEgo
}

\begin{abstract}
SUMARIO: I. INTRODUCCIÓN: 1.1 La natural ambigüedad de significado de las palabras que designan materias; 1.2 La cantidad de voces que designan materias en las reglas competenciales; 1.3 La falta de un criterio uniforme de sistematización; 1.4 La rigidez constitucional.-II. LA FUNCIÓN DE LAS MATERIAS EN NUESTRO SISTEMA DE DISTRIBUCIÓN DE COMPETENCIAS: 2.1 Introducción; 2.2 La pluralidad de técnicas para distribuir la competencia; 2.3 El problema de la base jurídica; 2.4 La relativa importancia de las materias en relación con otros criterios.-III. LAS MATERIAS COMO CONCEPTOS JURÍIICOS INDETERMINADOS: 3.1 El problema del encuadramiento; 3.2 La doctrina constitucional sobre el contenido inherente de las materias; 3.3 Las materias como conceptos que se refieren a la realidad social; 3.4 Las materias como conceptos jurídicos indeterminados; 3.5 La aplicación de las materias como un problema de comprensión; 3.6 La aplicación de las materias como un proceso dialéctico. -IV. LA INTERPRETACIÓN DE LAS MATERIAS CONFORME A LA LEGALIDAD ORDINARIA: 4. 1 Introducción; 4.2 Las normas reguladoras de una materia; 4.3 Los Reales Decretos de Traspasos y Transferencias; 4.4 Las normas de organización administrativa; 4.5 Las definiciones jurídicas contenidas en el ordenamiento jurídico; 4.6 Las sistematizaciones jurídicas doctrinales; 4.7 Conclusiones.-V. LA INTERPRETACIÓN DIRECTA de LAS MATERIAS POR el TRIBUNAL CONSTITUCIONAL: 5.1 Introducción; 5.2 La interpretación objetiva en el encuadramiento y sus insuficiencias; 5.2.1 El contenido de una norma; 5.2.2 El contenido de los actos; 5.2.3 Casos de interpretación objetiva realizada por el TC: a) En base a los presupuestos de hecho de las normas; b) En base a las consecuencias de las medidas; 5.2 .4 Insuficiencias de la interpretación objetiva de las materias; 5.3 La interpretación teleológica: 5.3.1 Finalidades de las normas y de los actos administrativos; 5.3.2 Casos de interpretación teleológica de las materias; 5.3.3 Insuficiencias de la interpretación teleológica. 5.4 La interpretación fenomenológica de las materias en el TC: 5.4.1 Introducción; 5.4.2 Casos de interpretación fenomenológica; 5.4.3 La característica más importante de la interpretación fenomenológica.-VI. LA INTERPRETACIÓN SISTEMÁTICA DE LAS MATERIAS: 6.1 Introducción; 6.2 El método sistemático y la cláusula de cierre del artículo 149.3;6.3 La interpretación sistemática en el problema del encuadramiento; 6.4 Las clases de relaciones que teóricamente pueden darse entre las materias: a) De inclusión, b) De exclusión, c) De conexión; 6.5 La interpretación sistemática de las materias en el TC.
\end{abstract}

\section{INTRODUCCION}

La distribución de competencias entre el Estado y las Comunidades Autónomas es la gran cuestión del Estado de las Autonomías. No puede dejar de ser de otra manera porque, en definitiva, lo que 
se ventila es quién detenta el poder político, y los problemas del poder, como indicaba Loewenstein en su teoría de la Constitución, hunden sus raíces en los sentimientos más hondos del ser humano (1). Por ello es perfectamente comprensible la vehemencia o la pasión con la que dicha distribución se presenta en la vida política práctica, pues, en último extremo, lo que una norma competencial dice es que el poder pertenece al Estado o a las CC AA.

No obstante ser las cosas de este modo, sin embargo, en los países que tienen una trayectoria política democrático-constitucional, la distribución vertical del poder político ha alcanzado grandes dosis de racionalidad. Con independencia de las causas sociológicas, culturales o políticas de esta actitud, la mejor expresión de la racionalidad viene constituida por el hecho de que la distribución de competencias está fijada en unas normas jurídicas, preferentemente contenidas en la Constitucion, y garantizadas por un procedimiento de resolución de conflictos, en la actualidad concentrado en casi todos los ejemplos en un Tribunal.

Ciertamente, las decisiones que deba adoptar ese Tribunal, son decisiones que recaen sobre problemas políticos y sobre cuestiones políticas, pero, en la medida en la que existe una norma jurídica, un proceso jurídico y una fundamentación jurídica, las decisiones que se adoptan tienen esa fuerza vinculante, a la vez que pacificadora, que el Derecho proporciona a la vida social.

El grado de juridificación del problema de la distribución del poder entre diversos detentadores varía, sin embargo, en cada país en función de múltiples y diversas causas o razones. En Suiza, por ejemplo, y aunque la reforma de la Constitución exige un laborioso procedimiento, el sistema político es muy flexible, de modo que son frecuentes las reformas que se realizan para salvar un obstáculo juridico-constitucional (2). En los Estados Unidos de América, sin embargo, la Constitución ha permanecido invariable en lo que a la distribución de competencias se refiere, pero se ha producido una evolución en la jurisprudencia, es decir, en las normas subconstitucionales (3).

Con casi toda seguridad, el hecho de que los problemas del reparto del poder se resuelvan en este campo, y no mediante fuertes rupturas o revoluciones, tiene que ver con complejas causas extra o metajurídicas. Es decir, que el cumplimiento de la Constitu-

(1) K. LoeWenstein: Teoría de la Constitución, Ariel, Madrid, 1973.

(2) Vid. al respecto, J. F. AUBERT: Traite du Droit Constitutionell Suisse, pp. 234 y ss.

(3) Vid. el exhaustivo análisis de la doctrina jurisprudencial americana realizado por E. AlONSO GarCía en la interpretación de la Constitución, CEC, Madrid, 1984. Cfr. también i. BORRAJO INIESTA, «Preención: Conflicto de leyes en el federalismo norteamericano», en Comunidades Autónomas, op. cit. 
ción, o la solución de los conflictos mediante instituciones ad hoc, como son los Tribunales Constitucionales, son las consecuencias de otros fenómenos que se resumen en lo que LOEWNSTEIN llama el sentimiento constitucional (4). No obstante, es preciso reconocer que entre el sistema jurídico-constitucional y el sistema político pueden darse mutuas influencias que son difíciles de medir, de suerte que en ocasiones es la norma constitucional la que conforma la realidad política, mientras que en otras ocasiones, a la inversa, el sistema político impone un sentido a la norma constitucional. EI complejo tema de las mutaciones constitucionales es el mejor ejemplo de este fenómeno (5).

Desde una perspectiva jurídica, sin embargo, la cuestión principal es si en verdad es posible juridificar estos problemas, o, más limitadamente, hasta qué punto es posible hacerlo. La doctrina española se ha preocupado en los últimos años de estas cuestiones en relación con la jurisprudencia constitucional, pareciendo existir una cierta unanimidad en el sentido de que existen aspectos de la decisión judicial que difícilmente pueden ser sometidos a técnicas jurídicas clásicas, porque hay valores y principios que han de ser tenidos en cuenta (6).

Estos estudios, no obstante, son muy tangencialmente aplicables a los problemas de interpretación de las reglas competenciales. Lo son en la medida en la que entre tales reglas existen también principios, tales como la unidad de mercado, la igualdad de condiciones de los derechos fundamentales, o que la interpretación que se siga no puede vaciar de contenido las competencias de las CC AA. Pero el núcleo principal de la decisión sobre un problema competencial no hace referencia a ningún tipo de valores o principios, sino que parece, al menos a primera vista, que puede ser resuelto con técnicas tradicionales.

En efecto, ha sido comúnmente aceptado entre nosotros y la práctica totalidad de la jurisprudencia constitucional ha sido consecuente con ello (7), que el reparto competencial viene establecido

(4) Op. cit., p. 23.

(5) Vid. en relación con este problema la obra de P. DE VEGA La reforma constitucional y la problemática del poder constituyente, Tecnos, Madrid, 1985.

(6) Además de las citadas obras de ALONSO GARCia pueden señalarse los siguientes estudios: L. MARTín-RETORTILLO BAQUER, "Antiformalismo y enjuiciamiento efectivo en el sistema de la justicia constitucional», en RDP núms. 16 y 17, 1982/1983; A. E. PÉREZ LUÑo. "La interpretación de la Constitución», en RCG núm. 1, 1984; F. J. EZQUIAGA GANUZAS, "La argumentación en la Justicia constitucional española», HAAE/IVAP, Onati, 1987; Vid., igualmente, las obras colectivas publicadas por la Dirección General de lo Contencioso del Estado: El Tribunal Constitucional, Madrid, 1981; y Las Comunidades Autónomas, Madrid, 1979.

(7) Desde el punto de vista doctrinal sigue siendo obligada la referencia a $\mathrm{S}$. MUÑoz MACHADO. Derecho público de las Comunidades Autónomas, Civitas, Madrid, 1982. Para una exposición general de la doctrina del Tribunal Constitucional, vid., en informe presentado por $F$. 
y regulado directamente por una serie de normas, a las que llamaremos competenciales, y que dicen, lisa y llanamente, que tal o cual sujeto tiene competencia sobre tal o cual materia. Que la decisión final que se adopte puede corregirse con arreglo a los principios antes mencionados, o con otras normas, como las que establecen los límites territoriales autonómicos, es indudable, pero las normas jurídicas que en primera instancia resuelven a quien corresponde realizar algo son esas citadas normas competenciales.

Dentro de esta norma competencial, la doctrina y la jurisprudencia han coincidido, igualmente, en señalar que se pueden distinguir dos elementos: las funciones y las materias. Las funciones son la clase de poderes que pueden ejercerse, tales como la legislación, la ejecución, las bases, la coordinación, la alta inspección, etc. Y la materia es, valga de momento y como introducción, el fenómeno social sobre el que se ejercen esas funciones: la agricultura, la sanidad, la propiedad intelectual, etc. Según esta división conceptual, la competencia de un sujeto (el Estado, la Comunidad Autónoma), es el resultante de tener atribuida una función sobre una materia.

Esta distinción conceptual no es, además, únicamente un instrumento técnico que permite hallar la clave de un problema, sino que constituye la base del esfuerzo por encontrar un método de interpretación y de aplicación jurídica de las normas competenciales, desprovisto de valoraciones y de la aplicacion de principios, cuyas deficiencias ya fueron apuntadas anteriormente. Pues, es un hécho que la doctrina sobre las bases, sobre la legislación, la ejecución o la coordinación, son posibles en la medida en la que se puede separar estos aspectos de una norma competencial de otros, como el de las materias.

El problema de las materias, en cuanto delimitadores de la competencia de los poderes públicos, radica en saber a qué se refieren, cuál es su contenido, o como dice MUÑOZ MACHADO «cuáles son los contornos de una materia, qué es lo que está incluido o excluido de la misma» (8).

En apariencia, este problema no debería presentar muchas dificultades. Así, si la regla competencial habla de los montes, las bibliotecas, las aguas, o la agricultura, parece que debiera entenderse que se refiere a todas las medidas que los poderes públicos puedan realizar y recaigan sobre dichos sujetos, objetos, espacios naturales o actividades. Sin embargo, lo cierto es que no sólo en

TOMÁS Y VALIENTE en la VI Conferencia de Tribunales Constitucionales Europeos de 1984, publicado en "Tribunales Constitucionales Europeos y Autonomias Territoriales», CEC/TC, Madrid, 1985.

(8) Op. cit., p. 372. 
España, sino también en los demás países federales o regionales, las dificultades para saber a qué se refieren las materias son muy grandes.

Las razones de que esto ocurra son muy variadas y pueden resumirse en las siguientes: la propia ambigüedad de las palabras y voces empleadas por las normas competenciales; la cantidad de materias mencionadas en dichas normas; y la rigidez constitucional.

\subsection{LA NATURAL AMBIGÜEDAD DE SIGNIFICADO DE LAS PALABRAS QUE DESIGNAN MATERIAS}

La mayor dificultad para la aplicación de las materias procede de causas intrínsecas. El constituyente y el legislador suelen utilizar una técnica muy sintética, de modo que las materias son palabras que se refieren a objetos, campos o ámbitos genérica y abstractamente mencionados. Así, por ejemplo, se habla de la ganadería, la agricultura, la industria.

Por supuesto, esta opción no es la única posible. En Suiza, por ejemplo, la distribución de competencias se realiza, a menudo, haciendo una extensa mención de la materia (9). $Y$ hay casos en nuestro sistema en los que así ocurre (confróntese los arts. 13 y 14 del EA de Cataluña, en los que se regula extensamente el reparto de competencias entre las policías autonómicas y estatales).

Lo normal, sin embargo, es encontrarse con una voz general, de modo que siempre es difícil saber a qué se refiere, dada la natural ambigüedad de las palabras, que pueden tener un significado anfibológico.

\subsection{LA CANTIDAD DE VOCES OUE DESIGNAN MATERIAS EN LAS REGLAS COMPETENCIALES}

Una segunda causa de que la aplicación de las materias sea más o menos compleja depende del número de materias previstas en las normas competenciales. En España la cantidad de voces que se refieren a materias es extraordinariamente grande, y ello viene determinado por el hecho de que las reglas competenciales están contenidas en lo que se ha llamado el bloque de la constitucionalidad, es decir, en la CE y en los EE AA.

Para hacernos idea aproximada de la cantidad de voces que designan materias en nuestro ordenamiento, hemos hecho un estudio meramente aproximativo de las contenidas en la Constitu-

(9) Vid., J. F. AUBERT, Op. cit., pp. 229 y ss. 
ción Española (10) y en el EAPV que ha dado el resultado de 170 materias (11). El volumen total de voces existentes en nuestro sistema autonómico es, sin embargo, mucho mayor, ya que hay que añadir las voces contenidas en la $C E$ y en los $E E A A$ restantes y no mencionadas en el EAPV. Además, en nuestro estudio hemos considerado como unidad a expresiones que pueden entenderse que incluyen a un conjunto de materias (por ejemplo, la voz «asociaciones benéficas, culturales, educativas, asistenciales y análogas»).

La razón de esta profusión de voces pudo deberse a la desconfianza del legislador autonómico que temió que la cláusula residual del artículo 149.3 de la $C E$, según el cual las materias no mencionadas en los EE AA serían de competencia estatal, fuese utilizada abundantemente en favor del Estado.

En cualquier caso, lo cierto es que el volumen tan grande de materias hace que la búsqueda de aquella que es aplicable resulte, a todas luces, ardua y difícil. Además, cuando existe tan gran cantidad de voces, la necesidad de encontrar una mínima sistematización parece imperiosa, ya que facilita su uso e interpretación.

\subsection{LA FALTA DE UN CRITERIO UNIFORME DE SISTEMATIZACIÓN}

Sin embargo, parece que todo intento de sistematizar las materias con una pretensión mayor que la de su mera exposición está abocada al fracaso. La constitución y los EE AA no siguen un criterio uniforme porque, como decía FRIEDRICH, el reparto de competencias es una cuestión de conveniencia en la que han influido todo tipo de factores políticos, económicos, sociales,

(10) El trabajo de aislar las voces que se refieren a materias no es fácil. Hay que tener en cuenta, primeramente, que las reglas competenciales no siempre son explícitas al mencionar una materia, porque no siguen la técnica de declarar que la CAPV tiene competencia sobre ... algo. sino que regulan extensamente una actividad. Asi ocurre, por ejemplo, con el artículo 17, relativo a la Policía Autónoma Vasca.

En segundo lugar, la regla general es que resulta fácil diferenciar funciones de materias, porque el EAPV a menudo da la competencia legislativa o ejecutiva sobre algo. Sin embargo. esta diferenciación es, a veces, muy difícil. Esto sucede, por ejemplo, con la expresión "ordenación». Cuando el EAPV habla de la ordenación farmacéutica o de la ordenación de los transportes, resulta sencillo distinguir entre la función (ordenación) y la materia (farmacéutica, transportes). Sin embargo, la expresión "ordenación del territorio» no puede ser descompuesta del mismo modo, so pena de dejarla sin significado. El criterio seguido ha sido el de aislar las voces sobre las materias hasta donde se haya podido llegar sin dejar de tener sentido.

En tercer lugar, cuando las reglas competenciales dividen una materia para repartirla entre el Estado y la CAPV con arreglo a los criterios del territorio y del interés, se ha considerado que estamos ante una sola materia distribuida y no ante dos materias distintas. Por lo tanto, no hay carreteras regionales (que discurren integramente en el territorio del PV) y carreteras estatales (que salen de dicho territorio), sino que hay una única materia «carreteras» distribuida con arreglo a este criterio.

(11) Vid. anexo con la lista de las voces sobre materias, clasificadas arbitrariamente en diversos sectores. 
culturales o ideológicos (12). De aquí que existan voces materiales que se entrelazan entre sí, o que están conectadas de tal forma que resulta difícil decidirse sobre la que es aplicable.

De hecho, nadie entre nosotros ha intentado realizar un estudio sistemático sobre las materias, salvo que se considere como tal a la obra de MARTín BASSOLS COMA llamada Código de los Estatutos de Autonomía de las Comunidades Autónomas (13), obra imprescindible para moverse en este bosque de voces, pero que se limita a ofrecer una relación de las materias, a título meramente expositivo y sin pretender, por supuesto, extraer consecuencias jurídicas.

$Y$, por su parte, el TC tampoco ha querido establecer una doctrina general explícita sobre las materias $y$, como ha señalado su actual Presidente, ha huido de construcciones que pudieran provocarle demasiados problemas. Por ello, el TC, después de dejar de manifiesto que ulas normas constitucionales y estatutarias relativas a la distribución de competencias clasifican la realidad social en materias para ordenar aquella distribución" (14) se ha limitado a enunciar el problema: «la técnica utilizada por la Constitución es compleja dada la coincidencia sobre una misma materia de intereses generales de diverso alcance, y dado que un mismo objeto es susceptible -generalmente- de ser situado en diversos campos» (15).

\subsection{LA RIGIDEZ CONSTITUCIONAL}

Los problemas de aplicación e interpretación de las materias contenidas en las reglas competenciales no son nuevos, sino que, al contrario, puede decirse que son los más comunes y corrientes en los sistemas federales y confederales. Ahora bien, parece existir una cierta regla no escrita que dice que la rigidez del sistema constitucional influye negativamente en el rigor interpretativo de las materias. Un ejemplo de esto puede venir de la mano de Suiza, cuyo sistema político es muy flexible, lo que permite a sus autoridades acudir a la reforma constitucional cuando se encuentran con un obstáculo insalvable en la interpretación de una norma constitucional.

Nuestra Constitución es muy rígida, sin embargo, no sólo porque los procedimientos de cambio sean más o menos complejos (el sistema suizo lo es en mucho mayor grado), sino porque y ss.

(12) C. J. FRIEDRICH, «Gobierno Constitucional y Democracia», IEP, Madrid, 1975, pp. 406

(13) Editado por el IEAL, Madrid, 1983.

(14) STC 125/1984, fj 1 (Hoteles).

(15) STC 22/dic./1981 (Bibliotecas). 
psicológicamente concebimos en la actualidad a la reforma constitucional como un fracaso político o como un riesgo para la estabilidad del sistema, o como una nueva apertura de problemas políticos todavía no resueltos, de modo que la reforma de la Constitución se considera como una posibilidad puramente teórica, $y$, en consecuencia, es la vía interpretativa la que se sigue para resolver los problemas.

\section{LA FUNCION DE LAS MATERIAS EN NUESTRO SISTEMA DE DISTRIBUCION DE COMPETENCIAS}

\subsection{INTRODUCCIÓN}

Se ha podido afirmar, creo que sin discusión, que "la materia se refiere a uno de los elementos de la competencia», o que "ses siempre un elemento sustancial de la competencia» (15). Y como ha señalado TOMÁS y VALIENTE «puesto que nuestro sistema competencial descansa sobre este concepto y la Constitución no lo define, es necesario saber cómo lo ha ido configurando el Tribunal, ya que en principio es claro que "la materia, como concepto jurídico relevante para definiciones competenciales, se erige en una de las líneas principales del sistema competencial"» (16).

Esta posición de principio parece que debería considerar que las materias cumplen una función de primera magnitud en orden a saber a quién corresponde la competencia para realizar algo o para decidir de quién es en un conflicto de competencia. Sin embargo, parece que en nuestro país el papel que cumplen las materias, como elemento de definición de competencias, no es tan importante como el que se da en otros países. Las razones son bastante claras.

\subsection{LA PLURALIDAD DE TÉCNICAS PARA DISTRIBUIR LA COMPETENCIA}

En efecto, es sabido que las técnicas para distribuir el poder pueden utilizar varios criterios. Lo normal en Derecho comparado es utilizar un reparto de materias, acompañado de un reparto de funciones. Pero como ya ha dicho MUÑOz MACHADO «tal vez el defecto más señalado de que adolece la Constitución española sea de un exceso de concentración de técnicas» (17), de tal modo que

(15) Vid. S. MUÑOZ MACHADO, op. cit., pp. 371 y ss.

(16) Op. cit., p. 188.

(17) Op. cit., p. 371. 
para saber de quién es la competencia en nuestro país es necesario realizar una auténtica investigación jurídica sobre:

- La materia en la que se incluye la medida (norma o actuación administrativa).

- La determinación de si la medida se debe calificar o no como básica cuando, conforme al apartado anterior, resulte que el reparto de competencias sobre la materia en juego ha sido distribuida con esta técnica (por ejemplo, en la sanidad según el art. 149.1.16).

- Si se trata o no de una medida legislativa o ejecutiva, cuando la materia está repartida con este criterio, como sucede con la propiedad intelectual (art. 149.1.9 CE).

- Si se trata o no de una medida de interés general o nacional o de interés autonómico, cuando la materia se ha distribuido con este criterio, como ocurre con las obras públicas (art. 149.1.24 CE).

- Si se trata de una materia de dimensión nacional o de carácter puramente territorial, como sucede con los transportes o las instalaciones eléctricas (art. 149.1.21 y 22, respectivamente).

La investigación no termina, sin embargo, cuando se realizan los pasos anteriores. Además habrá de tenerse en cuenta que si se concluye que la competencia parece corresponder a una Comunidad Autónoma, entonces todavía hay que indagar:

- Si la medida afecta o no a la igualdad de trato de los derechos y deberes de los ciudadanos, porque, en tal caso la acción puede ser de competencia estatal en determinados casos (arts. 139.1 y 149.1.1 CE).

- Si se trata o no de una medida que afecta a la libre circulación de personas y bienes (art. 139.2 CE).

- Si se trata de una medida que implica un ejercicio extraterritorial de las competencias de la Comunidad Autónoma (art. $137 \mathrm{CE}$ ).

Así pues, el reparto del poder rationae materia no es el único criterio a tener en cuenta en orden a tomar una decisión competencial, sino que es simplemente una de las técnicas empleadas por nuestro ordenamiento.

\subsection{El PROBLEMA dE LA BASE JURÍDICA}

Es más, en el estado actual de nuestro sistema competencial todavía está pendiente por aclarar la cuestión sobre si el Estado 
debe ampararse siempre en un título competencial específico para adoptar sus medidas, o si, como señalaba la STC 76/1983, «las Cortes Generales, como titulares de la potestad legislativa del Estado (art. 66.2 de la CE), pueden legislar en principio sobre cualquier materia sin necesidad de poseer un título específico para ello, pero esta potestad tiene sus límites derivados de la propia Constitución...»

En este sentido, MUÑOZ MACHADO ya había advertido que el TC había sentenciado a favor del Estado en alguna ocasión apelando a una serie de principios "cuya consecución exige la adopción de medidas de política económica aplicables con carácter general a todo el territorio nacional» (STC 28 de enero de 1981), fundamentación jurídica ésta que adolece de no indicar cuál es el precepto competencial que atribuye la competencia al Estado (18).

Ruptura de la necesidad de encontrar siempre una base jurídica a la competencia del Estado que se vuelve a repetir en la STC 146/1986 (Asistencia Social), en la que, después de un extenso análisis del conflicto $y$ de las normas constitucionales, llega a las siguientes conclusiones:

"Las materias incluidas en las resoluciones objeto de este conflicto, grosso modo y sin entrar en este momento en análisis de detalle, deben ser incluidas dentro del campo de la Asistencia Social; la "Asistencia Social" es competencia exclusiva de la Comunidad Autónoma gallega. No obstante, el Estado, en la medida que existan problemas sociales peculiares que requieran y exijan un planteamiento global, puede intervenir al respecto también mediante medidas de fomento, pero respetando las competencias propias de la Comunidad Autónoma.»

Así, pues, parece que en relación con el Estado, nuestro sistema competencial no es, estrictamente hablando, un sistema de atribución, como es, por ejemplo, el de la Comunidad Económica Europea (19), mientras que para las CC AA, al contrario, debe haber siempre una base jurídica expresa. Pues, como señalaba la

(18) Op. cit., p. 381

(19) Sobre las competencias de la CEE en general antes del Acta Unica Europea, vid A. TIZZANO: "Las competencias de la Comunidad", en Treinta años de Derecho Comunitario, CEE, Bruselas, 1981 , pp. 45 y ss. Sobre los efectos de la integración de España en el Mercado Común en el sistema de competencias del Estado y de las Comunidades Autónomas, vid. S. MUÑOz MACHADO: "La ordenación de las relaciones del Estado y las Comunidades Autónomas con la Comunidad Económica Europea», en Tratado de Derecho Comunitario, Civitas, Madrid, 1986, tomo I, pp. 571 y ss. Sobre la ampliación de las competencias de las CE después del Acta Unica, cfr. L'acta Unique Europeen, Journee d'etudes, Institut d'etudes europeennes, Bruxelles, 1986. y J. DE RUYT, L'Acta Unique Europeen, Université de Bruxelles, Bruxelles, 1987. 
STC 49/1984, en relación con las leyes estatales y autonómicas, «unas (las estatales), sin ámbitos limitados materialmente; las otras (las autonómicas), limitadas a determinadas materias» (f. j. 2).

El hecho de que el Estado no necesite una habilitación expresa en una norma competencial sustantiva o material, no significa que, sin embargo, la búsqueda de la materia aplicable deje de tener importancia, pues en el terreno jurídico se producen muy importantes consecuencias, si las medidas han sido dictadas sin dicha habilitación: cuando se trata de normas estatales, la consecuencia es que la norma se convierte en Derecho supletorio de los ordenamientos autonómicos; mientras que si se trata de normas autonómicas, la consecuencia es que la norma es declarada nula.

La cuestión es muy debatida en la doctrina, pues parece todavía prematuramente fuerte aceptar esta posición de supremacía del poder legislativo y normativo del Estado, pero jurisprudencialmente la tendencia es bastante clara, ya que siempre que el Estado vulnera unos ámbitos competenciales normativos de las CC AA el TC se ha limitado a declarar que la norma estatal no es aplicable en las CC AA, entendiendo por no aplicable a que tienen una vigencia meramente supletoria de las normas autonómicas.

\subsection{RELATIVA IMPORTANCIA DE LAS MATERIAS EN RELACIÓN CON OTROS CRITERIOS}

Jurídicamente, por lo tanto, la búsqueda de cual sea la materia aplicable es una cuestión previa que debe ser resuelta antes de abordar otras cuestiones, tales como si las medidas en conflicto entran o no en el campo de las facultades (legislativas, ejecutivas, básicas, territoriales) atribuidas en la norma.

Por ello, se ha podido decir que la búsqueda de la materia es una operación de calificación de las normas competenciales aplicables, similar a la que se produce en los sistemas de conflictos de leyes (20). Por ello, el TC, de modo muy general y reiterado, ha seguido estas premisas, de modo que ha intentado siempre definir cuál es la base jurídica que sustentaba la competencia del Estado o de las Comunidades Autónomas, razón por la cual ha buscado, primeramente, cuál es la materia aplicable, a partir de la cual ha podido adoptar su decisión.

Ahora bien, donde sí se ha producido una cierta devaluación de las materias es en el tratamiento procesal que el TC les ha dado cuando se ha tratado de saber cuál es la materia en juego. Sobre

(20) Vid. A. ARCE JANARIZ: Comunidades Autónomas y Conflictos de leyes, Civitas, Madrid, 1988, pp. 72 y ss. 
estas cuestiones volveremos más adelante, pues forman parte central de este trabajo, pero es preciso adelantar que nuestra más alta magistratura tiende a reducir los problemas de interpretación y aplicación de las materias a los casos en los que no tiene más remedio que entrar.

En efecto, de una parte, el TC ha eludido tener que pronunciarse sobre las materias cuando ha visto que la solución del caso no depende del encuadramiento, y esto, según F. TOMÁS Y VALIENTE, sucede cuando "es posible una interpretación sistemática entre diversos títulos competenciales concurrentes $y$, por ende, a veces cabe una aplicación conjunta de los títulos; cuando éstos son, por ejemplo, la sanidad y el medio ambiente, es imaginable una aplicación compatible entre diversos títulos, conducente por todos ellos a la misma solución respecto a la titularidad, o al menos a una solución modulada» (21).

Este método de razonamiento de economía mental, absolutamente legítimo, queda puesto de manifiesto en múltiples sentencias:

a) En la STC 71/1982, donde se dice que «la concurrencia de reglas determinará, en ocasiones, la exclusión de una; mas, en otras, la competencia, además de apoyarse en la definidora de competencias en el sector de la defensa del consumidor, podrá justificarse también por otra regla, lo que refuerza la solución».

b) En la STC 48/1985, en la que se discutía si una acción debía encuadrarse en dos materias, se declara que «... no es necesario realizar dicha opción excluyente, pues cabe perfectamente mantener, sin contradicción en cuanto a las consecuencias, que la cuestión-litigiosa puede encuadrarse en las dos materias aludidas -enseñanza y función pública-, como sostiene el representante del Gobierno vasco»r.

c) La misma doctrina es establecida en la STC 179/1985, a tenor de la cual dos títulos competenciales «pueden ser considerados inicialmente en el mismo plano, con perjuicio de que si fueran divergentes las consecuencias a las que se llegara, según uno u otro de estos títulos, hayamos de determinar cuál de ellos ha de ser considerado fundamentalmente o prioritario para nuestra decisión». En esa Sentencia, además, las consecuencias que se derivaban fueron las mismnas, de modo que el TC dejó sin resolver a qué materia pertenecía la acción discutida.

d) Y, finalmente, en la STC $87 / 1987$, en la que unas medidas de clasificación de películas cinematográficas y de material audiovi-

(21) Op. cit., p. 197. 
sual «entra, con naturalidad, en el ámbito comprendido bajo la rúbrica "espectáculos", sin perjuicio de que las mismas normas -considerando, desde otro punto de vista, la finalidad que ha guiado su adopción- pueden también ubicarse en el sector de la actividad pública aludido en el apartado 29 del citado artículo 9 ("ocio")...».

Decimos que es un método legítimo porque en estos casos las funciones o poderes atribuidos a los sujetos en las materias en conflicto eran las mismas (bases, legislación), resúltando así que era indiferente el encuadramiento, puesto que lo que había que resolver era si la medida entraba o no dentro de dichas funciones.

Por otra parte, el TC no ha entrado en los problemas de cuál es la materia aplicable porque, de un modo general, ha aceptado las tesis propuestas por las partes en el conflicto en orden a las materias que estaban en juego. De tal modo sucede esto que existen casos en los que el TC ha advertido que las partes no han tomado en cuenta una materia que puede ser aplicable al caso, a pesar de lo cual tampoco la ha utilizado (22). Y esta aceptación de las tesis de las partes ha de considerarse como un método general, ya que en los doscientos conflictos y recursos resueltos por el TC solamente he podido encontrar una excepción en la que el TC utiliza un encuadramiento no propuesto por las partes (23).

Esta tendencia, que no ha pasado inadvertida a las partes, ha obligado a que recientemente el TC deba aclarar que su actitud es puramente de respeto a las diversas posiciones mantenidas, sin que deba deducirse de ella una norma procesal importante:

«Esas distintas identificaciones competenciales carecen de efectos vinculantes para el Tribunal, pues el orden de competencias y la definición de las que, en cada caso, se ejerzan, no pueden quedar a merced de las alegaciones de las partes, sino que deben ser determinadas en atención a los criterios objetivos que sobre cada materia establecen la

(22) Así, en la STC $80 / 1985$ se dice que «... tomando sólo en cuenta los títulos competenciales aducidos por las partes, que en ningún caso han invocado otros que, como el de montes $y$ aprovechamientos forestales, guardan relación con la materia..." $Y$ en el mismo sentido se pronuncia la STC 179/1985, en la que se dice que «... ni siquiera como una regla atinente a la Hacienda General (art. 149.1.14 CE), conexión no sugerida por las partes pese a la obvia naturaleza fiscal de la norma contenida en el artículon.

(23) Se trata de la STC 153/1985, en la que se defiende la competencia del Estado en base al artículo 149.1.1 de la CE. Hay, sin embargo, un voto particular del Magistrado D. F. Rubio Llorente, en el que sostiene que el mero hecho de que el Estado no haya fundado su posición en el artículo 149.1.1 "bastaría para estimarlo inaceptable», lo que permite concluir que el modo de proceder del TC en esta Sentencia debe ser considerado excepcional y polémico. 
Constitución, los Estatutos de Autonomía y las leyes a las que éstos y aquélla remitan» (STC 69/1988, «Etiquetaje de productos en Cataluña», f. j. 2).

Parece claro que esta actitud puede ser adoptada por el Tribunal, a pesar de que en nuestro Derecho rige la máxima iura novit curia, porque su posición en los litigios está reducida a resolver unos casos planteados por las máximas instituciones políticas de nuestro sistema constitucional, y cuya naturaleza política no puede ser olvidada, de modo que el Tribunal puede limitarse a resolverlo en los mismos términos que han sido planteados por las partes (24).

\section{LAS MATERIAS COMO CONCEPTOS JURIDICOS INDETERMINADOS}

\subsection{INTRODUCCIÓN: EL PROBLEMA DEL ENCUADRAMIENTO}

No obstante tener un papel relativamente reducido, lo cierto es que los operadores jurídicos han de plantearse en alguna ocasión el problema que llamaremos del encuadramiento de una medida en una materia.

Utilizamos aquí la expresión encuadramiento porque ya ha sido utilizada por el TC (25) y porque nos parece que denota cuál es la característica principal de la operación intelectual: El encuadramiento es un juicio jurídico en el que se dice que «la medida $x$ pertenece a (debe encuadrarse en) la materia $X », 0$, dándole la vuelta a la proposición, que «la materia $X$ es aplicable a la medida Xy.

Este juicio opera con dos elementos. El primero de ellos es la medida, término que se utiliza en este trabajo como comprensivo de cualquier norma o acto, o conjunto de normas y actos, que tienen una unidad conceptual inescindible por su relación con unos fines. Respecto de la medida es irrelevante su forma jurídica lley,

(24) Obvio es decir, como señalaba Diez Picazo, que la posición del jurisconsulto o del abogado es mucho más difícil, ya que actúan en un estadio anterior en el que, atendiendo a las legítimas aspiraciones de su cliente, se trata de establecer la forma en la que se planteará el caso. Op. cit., p. 223.

(25) STC $48 / 1985$ f. j. 4 «... la cuestión objeto del presente conflicto (...) puede encuadrarse tanto en la materia relativa a la función pública como en la de la enseñanza o educación escolar...n 
reglamento, acto), a los efectos que estamos considerando, porque lo que importa es su contenido y sus finalidades (26).

El segundo elemento son las materias en las que aquellas medidas se pueden encuadrar. En pura teoría jurídica, este elemento es el que debería primar o ser decisivo, ya que es la norma jurídica la que ha de orientar o regir la vida política y social, y no la inversa. Por ello, parece que la decisión jurídica sobre el encuadramiento debe efectuarse siguiendo un camino deductivo en el cual se percibe cuál es el contenido de la materia y se concluye que el contenido de la medida debe encuadrarse en ella.

\subsection{LA DOCTRINA CONSTITUCIONAL SOBRE EL CONTENIDO INHERENTE DE LAS MATERIAS}

Sin embargo, la cuestión general y abstracta sobre lo que contiene una materia parece que puede ser abandonada o aparcada sin daño apreciable para el sistema. La razón podría ser que no sólo no es fácil saber cuál es el contenido de una materia, sino que ni es necesario ni probablemente es posible. Esto ha quedado puesto de manifiesto por nuestro Tribunal Constitucional.

En una de sus primeras sentencias el TC había declarado que «para solucionar las cuestiones que pueden plantearse hay que partir del contenido inherente a cada competencian (27). Se trata ésta de una declaración en la que hay implícito que las voces que se refieren a las materias tienen un contenido más o menos explícito, lo que es bastante obvio, ya que si no ocurriera así el edificio construido por las reglas competenciales se derrumbaría, ya que cualquier cosa podría pertenecer a cualquier materia. Por otra parte, esta declaración parece extraordinariamente lógica si se quiere conservar la fuerza jurídica de la Constitución y de los Estatutos de Autonomía, ya que primero se define cuál es el contenido de cada materia, y posteriormente se constata si la medida de que se trate encaja en ese título competencial.

En efecto, el TC ha establecido ya alguna doctrina importante sobre lo que en grandes líneas, grosso modo, pertenece a algunas materias, pero sus definiciones son siempre abiertas.

1. En materia de seguridad pública ha declarado que "se centra en la actividad dirigida a la protección de personas y bienes

(26) Sobre el concepto de medida y sus implicaciones en la distribución de competencias entre el Estado y las Comunidades Autónomas, vid. J. GARCíA TORRES, «La ordenación general de la economía, título sustantivo de competencia estatal», en REDC, número 17, mayo-agosto 1986, pp. 241 y ss., y E. ALBERTI ROVIRA: "Leyes medida y distribución de competencias: Un paso más en la interpretación extensiva de las "bases normativas" en la jurisprudencia constitucional», en REDC núm. 18, septiembre-diciembre 1986.

(27) STC 22/dic./1981.

REVISTA DE ESTUDIOS. -8 
(seguridad en sentido estricto) y al mantenimiento de la tranquilidad $\mathrm{u}$ orden ciudadano, que son finalidades inseparables y mutuamente coordinadas" (28). EI TC matizó después este concepto diciendo que uno toda seguridad de personas y bienes, ni toda normativa encaminada a conseguirla, o a preservar su mantenimiento, puede englobarse en el título competencial de seguridad pública, pues si así fuera la práctica totalidad de las normas del ordenamiento serían normas de seguridad pública, $y$, por ende, competencia del Estado, cuando es claro que se trata de un concepto más estricto, en el que hay que situar de modo predominante las organizaciones y medios instrumentales, en especial los Cuerpos de Seguridad a que se refiere el artículo 104 de la CE» (29).

2. En relación con la defensa de la competencia, wha de entenderse que comprende toda la legislación ordenada a la defensa de la libertad de competencia, mediante la prevención y, en su caso, represión de las situaciones que constituyan obstáculos creados por decisiones empresariales para el desarrollo de la competencia en el mercado» (30).

3. En relación con el tráfico y circulación de vehículos a motor, que "no se encuentran englobadas solamente las condiciones atinentes a la circulación (verbigracia: señales, limitaciones de velocidad, etc.), sino las condiciones que deben llevar los vehículos que circulan») (31).

4. En materia laboral ha declarado que «el concepto de legislación laboral (...) no puede ser entendido también como potencialmente ilimitado en función del segundo término, cosa que inevitablemente sucedería si el adjetivo "laboral" se entendiera como indicativo de cualquier referencia al mundo del trabajo. Es por ello forzoso dar a ese adjetivo un sentido concreto $y$ restringido, coincidente por lo demás con el uso habitual, como referido sólo al trabajo por cuenta ajena, entendiendo por consiguiente como legislación laboral aquella que regula directamente la relación laboral» (31).

5. En relación con la legislación mercantil ha establecido que «aquella habrá de incluir en todo caso la regulación de las relaciones jurídico-privadas de los empresarios mercantiles o comerciantes en cuanto tales» (32).

(28) STC 33/1982 (Coordinación sanitaria)

(29) STC 59/1985 (Tacógrafo).

(30) STC $71 / 1982$

(31) STC 59/1985 (Tacógrafo).

(32) STC 35/1982. 
EI TC no ha hecho, sin embargo, una declaración explícita acerca de cuál deba ser el contenido concreto y específico de las materias, ni ha establecido cuál sea el procedimiento a seguir para su determinación. Así, en la STC 39/1982, después de preguntarse lo "que entiende la Constitución por "materia" y cuál es el ámbito de lo laboral» aparca la cuestión diciendo que «sería aquí arriesgado y, previsiblemente, sujeto a ulteriores matizaciones que intentáramos la formulación de alguna regla con vocación de mayores generalizaciones. Además de ser esto arriesgado es innecesario...» (33).

Es decir, que se pueden resolver los problemas competenciales sin tener que definir lo que está contenido en una materia, porque basta encuadrar la disposición o actos impugnados en alguno de los títulos competenciales aducidos por las partes. De hecho, en la mayoría de los casos el TC se ha limitado a resolver cada caso concreto, sin pretender mayores generalizaciones, y ha abandonado el método de partir del contenido inherente de las materias para realizar el encuadramiento.

\subsection{LAS MATERIAS COMO CONCEPTOS QUE SE REFIEREN}

A LA REALIDAD SOCIAL

Las materias, por lo tanto, no predeterminan el contenido de las políticas de los poderes públicos simplemente porque no pueden prever, ni lo pretenden, lo que éstos deban realizar en cada momento. ¿A qué se refieren, entonces, las materias? La contestación más general dada por el TC es abierta y reconoce que se puede hablar de varias clases de materias:

a) Así, de un lado, las normas competenciales se refieren a «materias o actividades concretas del poder respecto de determinados fines sociales...» (34).

b) En segundo lugar, hay reglas que se refieren a «conjuntos normativos configurados según un criterio de clasificación de disciplinas jurídicas... (nos referimos a la legislación civil, a la legislación procesal)...) (35).

c) $\mathrm{Y}$, finalmente, hay casos en los que la Constitución «además del aludido criterio de distribución competencial, define competencias atendiendo a lo que es el objeto de la norma (la sanidad, por ejemplo)...» (36).

(33) STC 37/1981.

(34) STC 32/1981.

(35) STC $71 / 1982$ f. j. 2.

(36) STC $71 / 1982$ f. j. 2. 
Esta actitud abierta y prudente se confirma también en la prudencia doctrinal de nuestros mejores tratadistas, como MUÑOZ MACHADO, para quien «la noción debe ser interpretada con flexibilidad" y no existe un criterio uniforme. "Por el contrario, la materia es, en ocasiones, una actividad pública (las relaciones internacionales), un bien (aguas, minas, patrimonio histórico), el régimen de las relaciones jurídicas (público o privado), una técnica económica (planificación) o una actividad reflexiva del Estado sobre sí mismo (Administraciones públicas)» (37).

Como más adelante veremos, estos criterios diferentes pueden tener consecuencias jurídicas relevantes en orden a saber cuál es la materia aplicable a un caso concreto. Pero ahora quisiéramos señalar que, en último extremo, las materias se refieren a la realidad social sobre la que ejerce el poder político sus acciones, idea que también ha sido apuntada por una STC en la que se decía que «las normas constitucionales y estatutarias relativas a la distribución de competencias clasifican la realidad social en materias para ordenar aquella distribución» (38).

Se entiende aquí la expresión "realidad social» como un concepto opuesto al del «Estado», en la línea de la distinción «EstadoSociedad" que ha sido utilizada tan extensamente en nuestra ciencia jurídica y política, y creemos que refleja con bastante claridad por qué las materias son conceptos jurídicos indeterminados y por qué no es fácil saber cuál es su contenido.

\subsection{LAS MATERIAS COMO CONCEPTOS JURÍDICOS INDETERMINADOS (39).}

Utilizamos aquí la expresión "conceptos jurídicos indeterminados» en el sentido más general que la doctrina le ha dado, y que implica dos órdenes de cosas, como ha resumido ALONSO GARCiA: $1 .{ }^{\circ}$, que lo esencial de un concepto jurídico indeterminado consiste en que la indeterminación del enunciado no se traduce en una indeterminación de las aplicaciones del mismo, las cuales sólo permiten una unidad de solución justa en cada caso; $2 .^{\circ}$, que los conceptos jurídicos indeterminados contienen una zona de certeza, una zona de incertidumbre o penumbra, y una zona de certeza negativa (40).

(37) Op. cit., p. 371.

(38) STC

(39) Sobre los conceptos jurídicos indeterminados, vid. la completa monografía de F. SAINZ MORENO. Conceptos jurídicos, interpretación y discrecionalidad administrativa, Civitas, Madrid, 1976. Para su aplicación general en el Derecho, cfr. L. DíEZ PICAZO, en Experiencias juridicas y teoría del Derecho, Ariel, p. 265; para el campo administrativo, E. GARCIA DE ENTERRIA

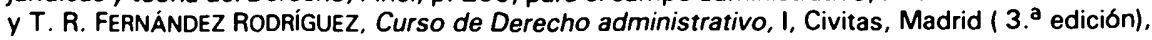
1979.

(40) Op. cit., pp. 116 y ss. 
En el núcleo conceptual estaría aquello que es mencionado por la materia y que identificamos de un modo determinado (por sanidad interior se entiende incluido todo lo relacionado con la salud humana), núcleo que va diluyéndose hasta hacerse indeterminado (en la sanidad interior puede estar incluida la sanidad animal), o que es precisado por contraste negativo con otras materias (en la sanidad no se incluyen las medidas relacionadas con los productos farmacéuticos).

La aplicación de la técnica de los conceptos jurídicos indeterminados a las materias parece que debe ser admitida sin excesivas dificultades. Si cada materia no tiene un núcleo o zona de juego más o menos preciso, todo el esquema competencial se cae por su propio peso, porque las medidas podrían encuadrarse en una $u$ otras materias, siendo estos encuadramientos igualmente legítimos. $Y$ en tal caso, la validez o nulidad de la norma sería discrecional no sólo para el TC, sino también para los demás operadores jurídicos.

Por ello, si se quiere que todas las normas competenciales tengan juego en el sistema competencial es preciso dar un significado jurídico a las materias, tal que lo que está encuadrado en ellas no pueda estarlo simultáneamente en las demás. Y esto es precisamente lo que la técnica de los conceptos jurídicos indeterminados implica: Que sólo hay un encuadramiento jurídica y constitucionalmente posible, aunque sea en ocasiones verdaderamente difícil encontrarlo.

Las materias pueden ser definidas como conceptos jurídicos indeterminados, además, sin reserva alguna, como ocurre con otros términos contenidos en la Constitución, en los que su concretización puede dañar o anular otros principios esenciales del sistema constitucional, como el del pluralismo político (41).

En efecto, no parece que pueda discutirse que las normas competenciales son disposiciones neutras desde un punto de vista material o sustantivo. Es obvio que afirmar la competencia estatal sobre las relaciones internacionales no predetermina cuál deba ser el contenido de dichas relaciones (si se ha de mantener relaciones internacionales como todas las naciones o si, al contrario, pueden restringirse en algunos casos; si ha de incorporarse o no a las organizaciones internacionales, etc.).

Una norma competencial es una norma que sólo dice a quién corresponde hacer las cosas, pero no que deba ser realizado por los poderes públicos. Aún más, es claro que el reparto de

(41) Sobre la tensión entre el pluralismo político y la necesaria única solución justa, vid, ALONSO GARCiA, op. cit. pp. 122 y ss. 
competencias es abierto y pluralista, en el sentido de que puede existir una variedad de opciones políticas, tanto de las instituciones centrales como de las instituciones autonómicas. Es decir, que en cada momento histórico los poderes públicos harán lo que les parezca más oportuno.

De aquí que la norma competencial, en cuanto a que se refiere a unas materias, no puede concretarse con claridad, porque en cada momento histórico las medidas varían en su contenido en función de circunstancias sociales, políticas, económicas o de cualquier índole. Puede existir un pluralismo incluso de políticas autonómicas, cuando la competencia legislativa corresponda a éstas. Pero la norma competencial no predetermina o condiciona esas políticas legislativas.

\subsection{LA APLICACIÓN DE LAS MATERIAS COMO UN PROBLEMA DE COMPRENSIÓN}

Una consecuencia relevante de que las materias sean referencias a la realidad social es que todo el proceso de interpretación o de aplicación viene a convertirse en un problema de comprensión, de intuición o de percepción de las cosas que no puede demostrarse de ningún modo, ni fundarse en criterios de carácter lógico.

En este sentido, pueden resultar muy apropiadas aquí las palabras de K. HESSE relativas a la posición del intérprete constitucional:

«El intérprete no puede captar el contenido de la norma desde un punto cuasi arquimédico situado fuera de la existencia histórica, sino únicamente desde la concreta situación histórica en la que se encuentra, cuya plasmación ha conformado sus hábitos mentales, condicionado sus conocimientos y sus prejuicios. El intérprete comprende el contenido de la norma a partir de una precomprensión que es la que va a permitirle contemplar la norma desde ciertas expectativas, hacerse una idea de conjunto y perfilar un primer proyecto necesitado aún de comprobación, corrección y revisión a través de un análisis más profundo, hasta que, como resultado de la progresiva aproximación a la "cosa" por parte de los proyectos en cada caso revisados, la unidad de sentido queda claramente fijada» (42).

Y estas palabras son enteramente aplicables al problema del encuadramiento de una disposición o acto administrativo entre dos

(42) K. HeSSE: Escritos de Derecho Constitucional, CEC, Madrid, 1983, p. 44. 
o más materias porque el proceso de decisión comienza con una hipótesis de trabajo condicionada por una precomprensión: La selección de las materias que son aplicables al caso. Selección inicial que después puede ser comprobada, corregida y revisada mediante un estudio más profundo sobre la legislación vigente, los antecedentes legislativos, los precedentes jurisprudenciales, la doctrina, etc. Todo lo cual va permitiendo una eliminación de unas $u$ otras materias hasta adoptar una decisión final sobre aquella que es aplicable.

\subsection{LA APLICACIÓN DE LAS MATERIAS COMO UN PROCESO DIALÉCTICO}

Pero la consecuencia más relevante de la consideración de las materias como conceptos jurídicos indeterminados referentes a la realidad social es que el proceso de decisión sobre cuál es la materia aplicable a un caso concreto (una medida), es un proceso dialéctico o circular en el cual se producen un ir y venir del contenido de la medida a las materias, y de éstas entre sí.

$Y$ esta tensión dialéctica entre los dos términos de la proposición jurídica del encuadramiento ha quedado bastante bien expuesta en seis conflictos de competencia, en los que se discutía si unas normas o unos actos administrativos que se referían al cine y al teatro debían de ser encuadrados en el ámbito material de los espectáculos (art. EAC), la cultura (arts. 148.1 y $149.2 \mathrm{CE}$ ), la adecuada utilización del ocio (art. EAC), los medios de comunicación social (art. 149.1 CE), y aun otros posibles, como son la potestad tributaria del Estado, la igualdad de condiciones de ejercicio de los derechos fundamentales (art. 149.1.1 CE), o la coordinación de la planificación económica (art. 149.1.13 CE). Se trataba así, pues, de un típico caso de encuadramiento de unos actos y unas disposiciones en una u otra materia, si bien algo más complejo de lo normal por la cantidad de títulos competenciales manejados (43).

El propio TC ha explicitado cuál ha sido el procedimiento seguido para resolver estas sentencias, pero sus declaraciones no han resultado muy claras. Así, en la STC 49/1984, decía que «las técnicas a utilizar para indagar cuál es la regla que debe prevalecer (...) tienen que tener muy presente, junto con los definidos ámbitos

(43) Se trata de las STC 49/1984, sobre calificación de películas; la STC 143/1985, sobre inspección cinematográfica; la STC $149 / 1985$, relativa a billetes de entrada en las salas de exhibición cinematográfica; la STC 153/1985, sobre calificación de espectáculos teatrales; la STC 87/1987, sobre películas cinematográficas y material audiovisual, y la STC 106/1987. sobre calificación de películas y concesión de licencias de doblaje. 
competenciales, la razón o fin de la norma atributiva de competencia y el contenido del precepto cuestionado...», declaración que se repite en las demás sentencias.

Parece, pues, que lo decisivo es indagar «la norma atributiva de competencia», buscando en ella no sólo el contenido más o menos objetivo, sino también, cuál es la finalidad. Sin embargo, después su procedimiento varía de hecho, ya que lo que tiene realmente en cuenta no es tanto la finalidad de la competencia, sino la finalidad de la disposición o actos objeto de la controversia, tal y como posteriormente aclaró en la Sentencia 106/1987, donde se dice qué título prevalente entre los que aducen las partes se debe decidir:

«En función del objeto y de la finalidad de las disposiciones $y$ actos traídos al conflicto.»

A pesar de estas vacilaciones, no parece ofrecer ninguna duda que el encuadramiento jurídico de una medida en una materia es un proceso dialéctico porque, en definitiva, se trata de subsumir un caso concreto (la medida) en una materia que se refiere a fenómenos sociales de un modo general o abstracto, de modo que da lo mismo decir que aquélla pertenece a ésta, o que, a la inversa, ésta engloba a aquélla, pues no parece posible saber si una medida concreta, por ejemplo una norma reguladora de los trasplantes de órganos, pertenece o no a una materia (por ejemplo, la sanidad) si no se tiene una idea general o abstracta (por mínima que sea) de lo que esa materia contiene.

Por otra parte, como existen muchas voces materiales en nuestro sistema competencial, es imprescindible tener en cuenta todas estas voces a la vez. Es decir, que es inevitable que el operador jurídico tenga presente una y otra vez a todas las materias cuya precomprensión le parece que es más oportuna. A este proceso le llamaremos interpretación sistemática.

Finalmente, la decisión sobre el encuadramiento, formulada con arreglo a los criterios anteriores, puede verse confirmada o corregida con arreglo a criterios indirectos, provenientes del ordenamiento jurídico en su conjunto, 0 , incluso, de otras ramas del saber no jurídicas, posibilidades éstas que no cabe excluir de plano en un dilema jurídico-constitucional como éste porque, como se vio, en definitiva lo que está en juego es una concepción de la realidad social. 


\section{LA INTERPRETACION DE LAS MATERIAS CONFORME A LA LEGALIDAD ORDINARIA}

\subsection{INTRODUCCIÓN}

Como es sabido, la apelación al ordenamiento jurídico precedente o existente para resolver los problemas de encuadramiento de las materias es ampliamente utilizado por los Tribunales Constitucionales comparados (44).

El caso más evidente es Austria, cuya doctrina sobre la petrificación es una especial forma de interpretación histórica, según la cual los términos usados por el constituyente deben ser comprendidos según el significado que tenían en el momento en el cual fue utilizada esa palabra. $Y$ en la investigación histórica han de ser tenidas en cuenta todas las normas reguladoras de la materia o institución y que existían en el momento de la petrificación (45).

Igualmente, en Italia la Corte Constitucional ha considerado también que "el criterio hermenéutico fundado sobre una larga tradición legislativa puede ser de utilidad en la interpretación de las normas constitucionales, aunque no sea absolutamente vinculante» (46).

La utilización del ordenamiento jurídico precedente, al modo austríaco, o el existente, al modo italiano, puede ser un método de gran eficacia para resolver las dudas sobre la materia que es aplicable en dos sentidos. Por una parte, si deseamos saber cuál es el contenido inherente a una materia, resulta extremadamente práctico hacer un repaso de la normativa vigente, en la que encontramos definiciones jurídicas, sistematizaciones jurídicas, tratamientos unitarios y homogéneos. $E$ igualmente se puede acudir a la doctrina jurídica que, mediante sus estudios y jurisprudencia, ha precisado los conceptos generales de la materia que se trate. Se obtiene así una idea general de cuáles son las actuaciones que realizan los poderes públicos en dicha área y en un momento dado. $\mathrm{Si}$, además, se efectúa un estudio cronológico de esa legislación y de su doctrina, se podrá apreciar cómo ha variado el tratamiento jurídico de la cosa.

Por otra parte, si se quiere saber en cuál materia hay que encuadrar una disposición o acto concretos, resulta también un

(44) Para el uso del ordenamiento jurídico existente en los países anglosajones, vid. ALONSO GARCíA, op. cit., capítulo XII, pp. 477 v ss.

(45) Vid. "Metodi di interpretazione costituzionale: L'interpretazione degli articoli della costituzione austriaca sulle competenze degli stati e della federazione da un punto de vista federalistico», de C. BINDER en Le Regioni/a. XIV. núm. 4, agosto 1986, pp. 866 y ss.

(46) Op. cit., pp. 231 y ss 
argumento importante encontrar los textos legislativos en los que se inserta tal acción, el encuadramiento general de estos textos, las definiciones jurídicas de los mismos, los órganos administrativos que tienen encargada su actividad, etc.

Sin embargo, el TC español, aunque ha utilizado estos métodos, no ha querido ligarse expresamente a ellos y, como la Corte italiana, no los ha considerado vinculante. Así queda puesto de manifiesto si analizamos el valor que el TC ha dado a: Las normas reguladoras de una materia; los Reales Decretos de Traspasos o Transferencias; las normas de organización administrativa; las definiciones jurídicas, y las sistematizaciones jurídicas doctrinales.

\subsection{LAS NORMAS REGULADORAS DE UNA MATERIA}

En efecto, primeramente y por lo que se refiere a los textos legislativos reguladores de una materia, el TC ha utilizado este criterio muy pocas veces. Así, en la STC 71/1983 utiliza el criterio de la incorporación del Catálogo de Montes en la Ley de Montes y en su Reglamento, para hacer prevalecer que se trata de una manifestación de la materia de «montes» en relación con la materia de «Registros Públicos». En la STC 24/1985 tienen en cuenta lo previsto en los planes energéticos nacionales para considerar que una instalación de procesamiento de productos petrolíferos debe ser incluida en la materia de energía y no en la de instalaciones de energía.

El TC, no obstante, ha rechazado que un texto legislativo pueda contener toda la materia (47). Por otra parte, y en un sentido inverso, el que una medida o acción no esté prevista en un texto legislativo general regulador de una materia no impide que pueda incluirse en ella (48). Además, como resulta evidente, un texto legislativo puede contener preceptos adscribibles a diversas materias, aunque su propósito sea el de realizar una regulación uniforme de una materia principal. Así, el Estatuto Vasco del Consumidor y del Usuario contiene prescripciones que entran en el ámbito de las materias de "defensa del consumidor», "comercio interior», "sani-

(47) Ha declarado «que toda la regulación del Registro Mercantil, que incluye la determinación de los actos que han de tener acceso al mismo, es de carácter mercantil, cualquiera que sea la ley que la contenga y su denominación". Igualmente, en la STC 71/1982 se señala que "sería equívoco ceñir esta reserva (sobre la defensa de la competencia) a lo acotado en la Ley, hoy vigente, 110/1963, de represión de prácticas restrictivas de la competencia, pues ha de entenderse que comprende toda la legislación ordenada a la defensa de la libertad de competencia...) (f.j. 15).

(48) Así, en la STC $87 / 1983$ (f.j. 4) considera que la fijación de los horarios de las enseñanzas mínimas deben ser incluidas en la materia de educación, «aunque no se recoja explícitamente en el Estatuto de Centros Escolares». 
dad», «legislación civil», «legislación mercantil» y otras. El TC ha obviado, por tanto, este criterio como definitivo, aunque to ha utilizado en algún caso para apoyar sus conclusiones.

\subsection{Los Reales Decretos de Traspasos y Transferencias}

Los Reales Decretos de Traspasos y de Transferencias pueden cumplir un papel similar al que tienen las normas reguladoras de una materia, ya que uel contenido del Decreto en cuestión es útil para esclarecer qué contenido tenía la competencia administrativa que se discute cuando la ejercía el Estado» (STC 113/1983, f. j. 3): En este sentido, puede recordarse «el valor interpretativo -que naturalmente no puede prevalecer sobre las previsiones constitucionales y estatutarias ni vinculará este TC- de tales DD de TT que suelen contener con mayor o menor detalle una especificación de las funciones que recibe la CA y las que retiene el E (STC 48/1983).

Dicho valor interpretativo ha sido utilizado en varias ocasiones para apoyar el encuadramiento de una acción en una materia, como ocurre en las Sentencias citadas y en otras (49), pero adolece del mismo problema que en los textos legislativos, es decir, que en los DD TT no está todo lo que se refiere a una materia (50), ni sólo lo que en ellos se menciona es parte de esa materia.

Además, el uso interpretativo de los DD TT no es considerado como definitivo, pues «la distribución de competencias entre el $E$ y las CC AA viene establecida en la CE y en los respectivos EE AA, de modo que los DD de traspasos de servicios se limitan a transferir éstos y no transfieren competencias (51).

\subsection{LAS NORMAS DE ORGANIZACIÓN ADMINISTRATIVA}

Cuando el objeto de un conflicto es una norma con rango inferior a la Ley, la identificación de cuál es el órgano emisor y el Ministerio - Departamento que la dicta o propone puede ser un criterio más

(49) Vid. la STC 80/1985, en la que se dice que «sin ir más lejos, los Reales Decretos de transferencia núms. 22/1979 y 1674/1981, incluyen las disposiciones relativas a estos traspasos bajo la rúbrica "agricultura", en el primer caso, o se remiten en el segundo a las competencias de CAC "en materia de agricultura y ganadería" como título justificativo de las transferencias").

(50) Por ejemplo, el hecho de que una acción no esté prevista en un Decreto de traspasos no impide su incorporación a una materia, como fue declarado en la STC 87/1983 f.j. 3, en la que se dijo que "La conclusión es, por lo tanto, que la competencia para fijar las enseñanzas minimas lleva aparejada como medio natural para su ejercicio efectivo la de fijar los horarios mínimos, aunque esta última no se recoja explícitamente ni en el Estatuto de Centros Escolares ni tampoco aún en el Real Decreto 3195/1980, de 30 de diciembre, sobre transferencia de servicios en la materia al Gobierno vasco».

(51) STC 48/1983, que se refiere expresamente también a las STC núms. 26/1982 y 25 , $71,76,87,88$ y $133 / 1983$. 
a tener en cuenta para saber cuál es la materia en la que debe encuadrarse dicha disposición. Así lo ha entendido la STC $39 / 1982$, en la que se dice que «... y es que el Decreto, como acabamos de decir, está afirmando la naturaleza laboral de todo su contenido, Decreto que por esto procede del Departamento de Trabajo y fue su Consejero el que presentó el proyecto al Consejo en un implícito reconocimiento de su contenido laboral».

Ahora bien, el TC sólo ha mencionado el criterio orgánico para apoyar y confirmar la hipótesis formulada con otros criterios que ha considerado más relevantes, como en la STC $80 / 1985$, en la que, después de usar de otros argumentos, termina señalando que, «por último, y en la medida en la que pueda utilizarse este argumento, la adscripción orgánica del servicio estatal del que emana la resolución combatida, que es la DG de Producción Agraria, manifiesta a las claras el ámbito material en que tales disposiciones se encardinan» (la agricultura y no la sanidad como pretendía el Estado).

\subsection{LAS DEFINICIONES JURÍDICAS CONTENIDAS EN EL ORDENAMIENTO JURÍDICO}

El uso de las definiciones jurídicas contenidas en las leyes y demás disposiciones fue usado por el TC por primera vez en la STC $35 / 1982$, en la que se decía que «el concepto de legislación laboral (...) no puede ser entendido también como potencialmente ilimitado en función del segundo término, cosa que inevitablemente sucedería si el adjetivo "laboral" se entendiera como indicativo de cualquier referencia al mundo del trabajo. Es por ello forzoso dar a ese adjetivo un sentido concreto y restringido, coincidente por lo demás con el uso habitual como referido sólo al trabajo por cuenta ajena, entendiendo, por consiguiente, como legislación laboral aquella que regula directamente la relación laboral; es decir, para recoger los términos de la Ley 8/1980, de 10 de marzo, la relación que media entre los trabajadores que presten servicios retribuidos por cuenta ajena y los empresarios, en favor de los que, y bajo la dirección de quienes se prestan esos servicios, con las exclusiones y excepciones que en dicha Ley (art. 1.3) se indican».

Sin embargo, son tan pocos los casos (52) en los que se utiliza este criterio que resulta imposible considerarlo como concluyente.

(52) Para saber qué era la protección civil tuvo en cuenta «el Decreto de 29 de febrero de 1968, señalando que la "protección civil" está constituida por el conjunto de acciones dirigidas a evitar, reducir o corregir los daños causados a personas y bienes por toda clase de medios de agresión y por los elementos naturales o extraordinarios en tiempos de paz, cuando la amplitud y la gravedad de sus efectos les hace alcanzar el carácter de calamidad pública». (f.j. 2) de la STC/Protección civil. 


\subsection{LAS SISTEMATIZACIONES JURÍDICAS DOCTRINALES}

En la STC $71 / 1982$ se hace una referencia "a conjuntos normativos configurados según criterio de clasificación de disciplinas jurídicas presente de algún modo en el artículo 149.1 de la Constitución (nos referimos a la legislación civil, a la legislación procesal, etc.)l.

Ahora bien, «el contorno de los grandes sectores sistemáticos del ordenamiento jurídico no es, en modo alguno, preciso, y la referencia a estos sectores como criterio de delimitación competencial hace depender tal delimitación de la opción que se tome dentro de una polémica doctrinal siempre viva» (STC 16/1981). Por esta razón, para el TC uun problema tan necesitado de soluciones claras y firmes como es el de la determinación del ámbito de competencia de una CA no puede plantearse a partir de datos extrínsecos, sino, en cuanto sea posible, a partir sólo de nociones intrínsecas a la propia Constitución (STC 43/1982).

\subsection{CONCLUSiOnes}

Tal y como se ha podido apreciar hasta aquí, el TC no considera que el contenido de una materia o el encuadramiento de una acción en una materia pueda determinarse con seguridad y certeza atendiendo a criterios extrínsecos a la propia constitución, tales como las normas jurídicas, las sistematizaciones jurídicas, las definiciones jurídicas y similares. El ordenamiento jurídico vigente ayuda a fijar el contenido de una materia, pero no es un argumento definitivo, de modo que hay que acudir a otros métodos de interpretación.

Y en este sentido cabría señalar que el recurso al ordenamiento jurídico para encuadrar una acción entre dos o más materias puede suponer una contradicción lógica importante porque lo que hacen las reglas de competencia es precisamente declarar qué poder político es el llamado a legislar o a ejecutar la legislación, es decir, que distribuyen o reparten el ordenamiento jurídico. De modo que acudir a la legislación ordinaria para saber dónde se han de encuadrar las medidas previstas en ese ordenamiento supone, como ha señalado acertadamente ALONSO GARCíA, caer en un círculo vicioso (53).

(53) Op. cit., p. 515. 


\section{LA INTERPRETACION DIRECTA DE LAS MATERIAS POR EL TRIBUNAL CONSTITUCIONAL}

\subsection{INTRODUCCIÓN}

Como ha señalado KARL LARENZ, «la afirmación que se oye con frecuencia que los términos evidentes no precisan interpretación induce a error, ya que, prescindiendo de los nombres propios, la mayor parte de los términos del lenguaje usual y también del leguaje legal no son evidentes. Ya la constatación de que del sentido literal resulta "evidente" este 0 aquel significado es, por regla general, el resultado de una interpretación»" (54).

La evidencia en este sentido o implica una inconsciente interpretación, justificable si todos los que intervienen en un litigio consideran el punto de que se trate tiene un único e igual sentido, pero se convierte en una auténtica dejadez metodológica si el punto es discutido y discutible.

EI TC ha hecho poco uso de la obviedad de las cosas y, cuando ha ocurrido, puede decirse que no estaba del todo desencaminado, como ocurre en la Sentencia 32/1983, en la que se dice lo siguiente: "Que la protección de la salud, y dentro de este marco, la disciplina de los productos alimenticios es algo incluible dentro del conjunto de medidas de protección de consumidor es comúnmente aceptado, sin que sea menester para apoyar este aserto recordar aquí textos legislativos propios o regulaciones supranacionales y consideraciones disciplinares».

No obstante lo anterior, lo normal es que cuando el TC declara la evidencia sobre la pertenencia de algo en una materia lo haga sin rechazar otros argumentos (55). E incluso hay un caso excepcional en el que se produce por primera vez una variación en la doctrina. En la STC $32 / 1983$ se afirmaba que «aunque las epizootias o

(54) K. LARENZ: Metodologia de la Ciencia del Derecho, ed. Ariel, 2. a edición 1980, p. 341.

(55) Así ocurre, por ejemplo, al tratar de definir cuál es el contenido del Derecho mercantil dijo que: "No es necesario, para dar solución a la controversia aqui planteada, entrar en ulteriores precisiones acerca de cuál sea el criterio adecuado para trazar los límites entre la legislación mercantil y la legislación correspondiente a otras ramas del Derecho, pues es claro que sea cual sea el criterio que se adoptase, aquélla habrá de incluir en todo caso la regulación de las relaciones juridico-privadas de los empresarios mercantiles o comerciantes en cuanto tales" (STC 16/Nov./1981).

Igualmente en la STC 179/1985 se afirma que «sea cual fuere el contenido que el concepto de Hacienda General se atribuya, no parece discutible, en efecto, que haya de incluirse dentro del mismo una medida que tiene por objeto directo la relación entre la Hacienda del Estado y las Haciendas Locales" (f.j. 1). Y más adelante añade que la "competencia de Hacienda General del artículo 149.1.14 CE comprende obviamente la regulación de los impuestos estatales, tanto en sus aspectos principales o fundamentales como en los accesorios o accidentales) (f.j. 3). 
plagas hayan de afectar al campo o ganado, es obvio que la coordinación de las medidas para combatirlas son también competencia en materia de sanidad». Sin embargo, en otra Sentencia posterior el TC mantuvo con abundantes argumentos jurídicos y no jurídicos que la sanidad vegetal debía ser encuadrada en la agricultura, corrigiendo asi una conclusión que dejaba mucho que desear respecto a su obviedad y evidencia.

Puede afirmarse por ello que nuesto Tribunal está realizando un permanente esfuerzo por seguir una metodología jurídica precisa para fundamentar sus afirmaciones a través de diversos criterios, como son la interpretación objetiva, la interpretación teleológica y la interpretación teleológico-objetiva.

\subsection{LA INTERPRETACIÓN OBJETIVA EN EL ENCUADRAMIENTO Y SUS INSUFI- CIENCIAS}

La interpretación objetiva de las materias en el sentido que aquí se le está dando significa que una medida cualquiera es encuadrada en una materia en base a su contenido natural u objetivo, prescindiendo por completo de cuales sean las finalidades que se pretendan con aquellas medidas.

Ahora bien, la expresión "contenido de las medidas» es muy vaga y parece necesario recordar aquí en qué consiste éste en términos generales.

\subsubsection{El contenido de una norma}

Según la doctrina más extendida, el contenido de una norma jurídica es siempre identificable en dos elementos: Un presupuesto de hecho y una consecuencia jurídica. Sobre este aspecto no parece haber muchas dudas en nuestra cultura jurídica (56).

El presupuesto de hecho es en este sentido la realidad social, los fenómenos, los sucesos contemplados en la norma y que si se dan (si ocurren) producen la consecuencia prevista en la propia norma. Así, por ejemplo, en la norma que establece la obligación de la previa clasificación de las películas por edades para su exhibición pública, el presupuesto de hecho es la voluntad de un titular de los derechos de explotación de una película de exhibirla públicamente,

(56) Cfr. Castro y Bravo: Derecho civil de España, 1955, p. 61. L. Legaz Y LACAMBRA, Barcelona, 1979, p. 380, L. RECASÉNS SICHES: Introducción al estudio del Derecho, Méjico, 1979, p. 124, L. Diez PICAZO: Experiencias jurídicas y teoría del Derecho, Barcelona, 1982, p. 61. Nuestros autores suelen fijar sus posiciones, corrientemente, por contraste con la doctrina alemana $y$, significadamente, con Kelsen. En relación con la doctrina alemana contemporánea, cfr. KAR LARENZ, op. cit., pp. 242 y ss. 
momento a partir del cual nace la obligación de clasificarla por edades, que es la consecuencia jurídica de la norma.

Dentro del presupuesto de hecho es donde, por tanto, se pueden identificar a su vez otros elementos, tales como el sujeto $u$ objeto al que se refiere, o la conducta que reglamenta.

\subsubsection{El contenido de los actos}

En relación con los actos administrativos, la cuestión puede ser más compleja, por cuanto que es claro que, como señala GARCIA de ENTERRIA, hay que distinguir entre el presupuesto de hecho, el contenido (strictu sensu) y el objeto del acto (57).

El presupuesto de hecho de los actos no está en ellos, sino en las normas administrativas que habilitan a la Administración a actuar. Así, siguiendo el ejemplo anterior, el acto administrativo de clasificación de las películas tiene como presupuesto de hecho la voluntad de un interesado de exhibir dicha película, que está en la norma, y que se concreta en una solicitud ante la Administración para que actúe.

El contenido (en sentido estricto) del acto administrativo es una declaración que puede ser de voluntad, o de juicio, de conocimiento, de deseo. En el caso que consideramos, el contenido es la calificación (un juicio) de las películas. Y el objeto es la cosa, hecho, conducta, situación jurídica sobre la que recae la declaración, es decir, la película.

\subsubsection{Casos de interpretación objetiva realizada por el TC}

Teniendo en cuenta que el contenido de una norma o acto es complejo, una depurada técnica de encuadramiento vendría a precisar cuál de sus elementos es el que ha de considerarse como más relevante para saber cuál es la materia aplicable. Sin embargo, lo cierto es que el TC no ha seguido esa técnica uniforme, pues hay casos en los que el elemento decisivo de la medida se ha encontrado en el presupuesto de hecho, mientras que en otros casos el elemento ha sido la consecuencia jurídica prevista.

a) En base al presupuesto de hecho.

Los casos más claros de interpretaciones objetivas en las que lo determinante era el presupuesto de hecho de la medida son dos:

El primero se encuentra en la STC 125/1984, en la que se discutía si la calificación de los hoteles en diversas categorías era

(5i) Op. cit., pp. 348 y ss. 
una actuación encuadrable en la materia de turismo o del comercio exterior, y el TC sentenció que «la finalidad de la norma en cuanto vincula sólo débilmente con el comercio exterior, debe ceder en este caso frente a su contenido material, esto es, obliga a interpretarla como norma que disciplina la actividad turística».

El segundo está en la STC número 59/1985 (tacógrafo); la Junta de Galicia había dictado una disposición excluyendo de la obligación impuesta por una norma estatal de instalar un tacógrafo en todos los vehículos de transporte escolar que realizaran un recorrido menor de $\mathbf{5 0}$ kilómetros. Para la Junta se trataba de una medida encuadrable en la materia de transportes. Para el Estado, la finalidad de la disposición estatal es la de garantizar la seguridad en los transportes escolares y, por lo tanto, sería encuadrable en el ámbito del artículo 149.1.29 de la CE (seguridad pública). EI TC opina, sin embargo:

«No toda seguridad de personas y bienes, ni toda normativa encaminada a conseguirla o a preservar su mantenimiento puede englobarse en el título competencial de "seguridad pública", pues si asi fuera, la práctica totalidad de las normas del ordenamiento serían normas de seguridad pública $y$, por ende, competencia del Estado, cuando es claro que se trata de un concepto más estricto en el que hay que situar de modo predominante las organizaciones y los medios instrumentales, en especial los cuerpos de seguridad, a que se refiere el artículo 104 de la Constitución.»

EI TC terminó 'concluyendo que la medida en cuestión era encuadrable en la de "tráfico y circulación de vehículos a motor».

En estos casos es patente que el encuadramiento se realice sobre la base de que las medidas recaen sobre unos sujetos (los hoteles, los vehículos de transporte) que se perciben como una clase de objetos mencionados por las materias respectiva (el turismo, el tráfico y circulación de vehículos). El paso que va desde el presupuesto de hecho de la norma, que es muy concreto, y la materia aplicable, que es muy ambigua, puede ser, desde luego, muy complejo, pero parece que esta técnica es bastante precisa.

Por otra parte, hay que reconocer que la mera constatación de cuál sea el supuesto de hecho de una medida puede no ser decisivo. Por ejemplo, en unas medidas de lucha contra las plagas del campo, en las que se establecen una serie de obligaciones de hacer y no hacer, el presupuesto de hecho es la existencia de esas plagas del campo. Ahora bien, este presupuesto no nos dice nada 
acerca de cuál será la materia en la que tales medidas deban encuadrarse, si en la agricultura, si en el medio ambiente. Si nos fijamos en el espacio físico en el que recaen esas medidas, es probable que podamos concretar aún más el presupuesto de hecho: que puede ser un determinado cultivo (el trigo), o todo tipo de cultivos y de flora. En el primer caso, la materia que es más aplicable parece ser la agricultura, mientras que en el segundo permanece todavía la indefinición, si bien parece que la materia más apropiada es el medio ambiente.

\section{b) En base a las consecuencias de las medidas.}

En los ejemplos anteriores es patente, además, que las consecuencias de las medidas han sido poco relevantes. Sin embargo, hay otras Sentencias del TC en la que precisamente las consecuencias o efectos son determinantes.

El más claro de todos es el previsto en las Sentencias del TC $153 / 1985$ y $88 / 1987$. En ambas se discutía quién tiene la competencia para calificar las películas por edades, y el TC empieza diciendo que "tal objeto de normación entra con naturalidad en el ámbito comprendido bajo la rúbrica "espectáculos"...) (STC $87 / 1987$, f. j. 2), pero cuando examina los efectos de las normas, sus conclusiones son diferentes. La norma estatal establecía como posibles efectos de la calificación la prohibición de acceso de menores a determinadas películas, lo que se consideraba una restricción a la libertad de expresión (art. 20.1 CE) y entraba en el campo de la materia mencionada en el artículo 149.1.1. Sin embargo, como la norma autonómica tenía un carácter meramente indicativo, debía ser encuadrada en los "espectáculos».

Otro ejemplo igualmente claro, en el que son los efectos o consecuencias de las normas lo que se considera prevalentemente, es el de la STC 49/1984, donde se discutía quién debía realizar la calificación de películas de "arte y ensayo» y de películas "X»). También aquí para el TC el material natural sería la de «espectáculos», pero como los efectos de las medidas son de carácter fiscal (ventajas o gravámenes acentuados) la materia aplicable es la mencionada en el artículo 149.1.1 de la CE en relación con el artículo 31.1 (deberes fiscales) (58).

En términos generales, la objeción más importante que tiene esta técnica de encuadramiento consiste en que el Estado viene a tener un refuerzo muy considerable en su ámbito de competencias, ya que sólo él puede usar una serie de instrumentos de intervención

(58) Vid. STC $49 / 1984$ y STC $87 / 1987$ 
(las medidas fiscales, las restricciones de derechos), instrumentos éstos que, además, pueden ser verdaderamente eficaces como ordenadores de la vida social sin que puedan las CC AA echar mano de ellos.

\subsubsection{Insuficiencias de la interpretación objetiva de las materias}

Con todo, las mayores dificultades de la interpretación objetiva derivan de dos problemas que esta técnica no puede resolver: el que el contenido de una medida puede apuntar a diversas materias, $y$ el que un mismo fenómeno puede ser intervenido desde distintos puntos de vista.

En efecto, la decisión jurídica a partir del contenido de la medida sigue siendo problemática, porque dicho contenido no es simple, sino que es complejo y puede ocurrir que haga referencia a varias cosas (presupuestos de hecho, sujetos, causas, fines, objetos y consecuencias jurídicas), cada una de las cuales puede ser encuadrada en una materia distinta.

Por ejemplo, una disposición que regula la actividad de las Cajas de ahorro, se refiere a un sujeto (las Cajas de ahorro), a un supuesto de hecho (la actividad crediticia o monetaria) y establece unas consecuencias jurídicas (por ejemplo, limitaciones en el volumen de fondos crediticios y ventajas fiscales en relación con algunos créditos). Cada uno de estos elementos puede dar lugar a un encuadramiento de la acción en materias distintas: Cajas de ahorro, crédito, política monetaria, igualdad de deberes fiscales.

$Y$ cuando se aprecia esto, que es bastante frecuente, no hay razón alguna que justifique que deba utilizarse uno de estos elementos y no el otro.

Por otra parte, resulta que un objeto, una cosa, puede ser regulada o intervenida desde distintos puntos de vista, cada uno de los cuales responde a una materia distinta (59).

Pues, en efecto, a nadie se le escapa que un mismo sujeto, por ejemplo, una empresa de fabricación de productos farmacéuticos, da lugar a numerosas normas e intervenciones de los poderes públicos de signo muy diferente. En cuanto que empresa mercantil está sometida a las normas del Derecho mercantil; en cuanto que empresario, a las normas de Derecho laboral; sus centros fabriles, en cuanto que centros de trabajo están sometidos a las normas de seguridad e higiene en el trabajo; la ubicación de dichos centros, en

(59) Utilizamos aqui la expresión método del punto de vista en el sentido que lo emplea C. BINDER al resumir los métodos de interpretación del Tribunal Constitucional austríaco. Op. cit., pp. 885 y ss. 
cuanto que esta empresa produce residuos contaminantes, está sometido a las normas urbanísticas y medioambientales; los productos que fabrica están regulados en normas técnico-sanitarias; etcétera.

La apreciación de que sobre un mismo objeto pueden ejercerse competenciales materiales diferentes fue reconocida expresamente por el TC en la STC 113/1983 (Inspección Pesquera) en la que se dice que:

«...sobre un mismo ámbito y sobre las personas que en él actúen y las actividades jurídicamente relevantes que en él se desarrollen es posible concebir distintas competencias atribuibles a también distintos órganos. (...) En pura lógica, pues, sobre un mismo ámbito jurídico caben distintas competencias de órganos diferentes, y esta posibilidad no se destruye, antes bien se potencia, con la actual organización competencial del Estado, algunas de cuyas competencias previas a la CE permanecen residenciadas en órganos strictu sensu esttales, mientras que otras han pasado a corresponder a la CCAA.»

Es por estas deficiencias, quizás, que la interpretación objetiva no parece tener un predicamento importante en nuestro TC y se han empleado con bastante frecuencia los criterios teleológicos.

\subsection{LA INTERPRETACIÓN TELEOLÓGICA}

5.3.1 Finalidades de las normas $y$ de los actos administrativos

En relación con las finalidades de las normas y los actos administrativos parece existir una cierta opinio iuris commune. Ahora bien, para precisar cuál es la finalidad de una medida, conviene distinguirla de las funciones del Derecho y del ordenamiento jurídico.

Como es sabido, los teóricos de Derecho han estudiado con bastante profundidad cuál es la función que cumple éste en el marco general de la Sociedad. Se habla, así, de que el Derecho tiene una función pacificadora, una función de resolución de conflictos, una función promocional, o más clásicamente, una función de garantizar la justicia. Estas investigaciones, como señala N. BOBBIO (60), entran más en el campo de la sociología que de la dogmática jurídica. La función de una norma y de un acto administrativo, en este sentido, no es diferente de la que tiene

(60) Contribución a la Teoría del Derecho, Fernando Torres ed., Valencia, 1980, pp. 143 y ss. 
todo el ordenamiento jurídico $y$, por ello, carece de interés para nosotros.

Cuestión distinta es que todas las normas y todos los actos administrativos tienen una finalidad, en el sentido de que son medios idóneos para alcanzar un objetivo. Esta idea no parece que pueda negarse, salvo que se mantenga una concepción tan idealista del derecho que lo haga inviable en su aplicación práctica. El legislador, en efecto, dicta la norma para conseguir algo. Establece la obligación de fumigar el campo y sacrificar las zonas contaminadas, para luchar contra las plagas del campo. Clasifica las películas por edades para proteger a la infancia y la juventud. Establece un sistema de ayudas para el abandono de la producción lechera, para equilibrar el sistema de producción/consumo en este sector.

En relación con los actos administrativos, también es conocido que, además de estar toda la actuación administrativa in genere dirigida a servir con objetividad a los intereses generales, cada acto concreto debe servir o adecuarse a la finalidad específica para la que fue habilitada la Administración. Señalan, en este sentido, GARCÍA DE ENTERRÍA y FERNÁNDEZ que la finalidad varía en cada sector específico: en la potestad de policía, la seguridad pública; en las potestades sanitarias, la salubridad, etc. (61).

Es claro que la existencia de estos fines concretos y específicos de cada norma o acto son la base permanente de una interpretación teleológica de las normas, interpretación dirigida a extraer su sentido y a aplicarlas, normalmente, a un caso concreto. Por ejemplo, si la norma establece la obligación de restauración de los espacios físicos dañados por las actividades mineras, puede considerarse que esta medida está destinada a preservar una calidad ambiental y que, en consecuencia, también están obligados a realizar esa restauración las actividades que, aun cuando no sean estrictamente mineras, dañen igualmente los espacios físicos (62).

\subsubsection{Casos de interpretación teleológica de las materias}

Con una interpretación teleológica lo decisivo son los fines que se pretenden en las disposiciones o resoluciones, aun cuando su contenido apunta a otra materia.

Un caso en el que esto ocurre es el de la STC 80/1985, en la que se considera que la lucha contra las plagas del campo debe calificarse como materia de agricultura uen primer lugar, porque las medidas de protección y prevención de la sanidad vegetal y, muy

(61) Op. cit., pp. 1136 y ss.

(62) Sobre la aplicación de la interpretación teleológica en la resolución de los casos, vid., además, KAR LARENZ, op. cit., pp. 331 y ss. Sobre la aplicación general del argumento teleológico en el Tribunal Constitucional, F. J. EZQUIAGA GANUZAS, op. cit., pp. 365 y ss. 
en concreto, la lucha contra las plagas vegetales tienen como fin primordial, cuando no exclusivo, la defensa y fomento de la producción agrícola» (f. j. 1). Obsérvese que el TC tuvo en cuenta no tanto el hecho de que la lucha contra las plagas del campo se refirieran a la actividad agrícola (lo que hubiera supuesto una interpretación objetiva), sino al hecho de que la finalidad de esta acción es la de fomentar y defender la producción.

La finalidad de las normas y de las actuaciones administrativas está presente también, aunque sea de modo implícito, en la STC 56/1983, sobre la competencia para autorizar a un Ayuntamiento a otorgar avales, en la que, después de realizar un análisis extenso de la legislación vigente, el TC concluye que «la autorización (...) se orienta a verificar si concurren los presupuestos que permiten otorgar el aval, sin estar implicados los objetivos a que responde la competencia reservada en el art 149.1.11 (o en el artículo 149.1.13).

Igualmente, en la STC 64/1982, donde la cuestión consiste en encuadrar una ley catalana protectora de espacios de especial interés natural dañados por actividades extractivas en la materia de «medio ambiente» o de "espacios naturales», dice el TC que:

"Si se compara esta regulación (la de la ley catalana) con la prevista en la Ley de Espacios Naturales Protegidos y su correspondiente Reglamento resultan diferencias esenciales entre ambos tipos de regulación. La Ley impugnada establece medidas de protección basadas en el principio de restauración respecto a las consecuencias del ejercicio de una determinada categoría de industrias, las industrias extractivas, que se presentan como un refuerzo de esa protección respecto a las que se prevén con carácter general en una ley futura. Por el contrario, la legislación sobre espacios naturales se basa en la idea de conservación de la naturaleza... Procede, por tanto, descartar del presente debate los temas relativos a la competencia de la Generalidad en materia de espacios naturales protegidos $y$, en particular, el alcance del artículo 9.10 del EAC en relación con el artículo 149.3 de la CE...» (f. j. 3).

\subsubsection{Las insuficiencias de una interpretación teleológica}

Es patente en la interpretación teleológica seguida por el TC en estas sentencias, que las normas y las acciones administrativas son medios para cumplir con algunos fines (se prohíbe el acceso de los 
menores de edad a algunas películas como medio que evita un daño a su sensibilidad). $Y$, en tal sentido, el objeto de la acción o de la norma no es importante, sino que lo es solamente su finalidad.

Sin embargo, respecto del problema concreto que estamos estudiando, que es el encuadramiento de una acción en una materia concreta, la finalidad de las normas y de las acciones no aporta nada, salvo que se tenga una concepción teleológica de las materias.

En efecto, si se considera que una medida que establece la obligación de que las empresas de producción química y farmacéutica se ubiquen a una distancia determinada de los núcleos urbanos, pretende principalmente preservar la salud de la población, la materia aplicable será la sanidad, quedando relegadas otras eventuales materias, tales como el medio ambiente, y la contaminación. Ahora bien, es obvio que una decisión de este tipo está diciendo que pertenecen a la sanidad todas las medidas que adopten los poderes públicos $y$ que pretendan, principalmente, preservar o salvaguardar la salud pública. Es decir, que se está manteniendo una concepción teleológica de las materias.

Resulta claro que esta interpretación da una respuesta muy satisfactoria a la objeción proveniente de los distintos puntos de vista de las medidas adoptadas por los poderes públicos y que recaen en un mismo objeto, hecho, actividad o sujeto. Empero, metodológicamente hablando, el problema es cómo saber cuáles son los fines que se corresponden con cada una de las materias porque, como ya se dijo anteriormente, como mucho, indican tareas o asuntos, pero son neutrales en cuanto a lo que concretamente deban hacer los poderes públicos en un momento dado. Así, atribuyen competencia en materia de transportes, pero no dicen que las normas reguladoras del transporte deban establecer que los transportes son un servicio público y que, por ello, estén sometidos a previa autorización o concesión. En cualquier momento dado, los poderes públicos pueden entender que esto no es necesario y que, por lo tanto, la prestación de este servicio sea libre.

Los fines que deban alcanzar los poderes públicos al dictar las normas o realizar sus actuaciones, pueden estar señalados en otros artículos de la Constitución; por ejemplo, en el capítulo tercero del título primero, llamado "De los principios rectores de la actuación de los poderes públicos», pero no en las normas competenciales.

$Y$ si las normas competenciales no dicen nada sobre los fines que deban alcanzarse, tampoco parece lícito señalar que pertenecen a la materia $X$ las medidas que tengan, principalmente, la 
finalidad $x$. De donde se deduce que el encuadramiento de una medida en una materia no se puede realizar atendiendo a los fines que se pretendan por éstas.

\subsection{LA INTERPRETACIÓN FENOMENOLÓGICA DE LAS MATERIAS EN EL TC}

\subsubsection{Introducción}

Se pone de manifiesto, de las consideraciones anteriores, que existe una antinomia en las interpretaciones objetiva y teleológica de las materias. Si las materias se refieren a los presupuestos de hecho de las medidas que adoptan los poderes públicos, no se puede abordar con satisfacción el problema de que pueden darse varias medidas que recaigan sobre un mismo objeto, fenómeno o sujeto, atendiendo a diversos puntos de vista.

Y si, para resolver este problema, se acude a una interpretación teleológica de las materias, se está otorgando a las reglas competenciales una fuerza jurídica que no les corresponde: La de determinar qué fines deban realizar los poderes públicos.

Esta antinomia, al parecer, sólo puede resolverse replanteándose qué es lo que dice una norma competencial cuando señala que el Estado o una CA tiene competencia (exclusiva, compartida o concurrente) en materia de $x$. $Y$ este replanteamiento parece que puede ser suficiente si volvemos a recordar que lo que las reglas competenciales hacen es repartir las tareas de los poderes públicos, de modo que a unos les corresponde hacer unas cosas y a otros otras. Estas cosas son siempre normas o actos que recaen sobre unos fenómenos, unos presupuestos de hechos, respecto de los cuales determinan unas consecuencias jurídicas, y que pretenden alcanzar unos objetivos que se fijan los poderes públicos en un momento concreto, objetivos éstos que se perciben como inherentes, inmanentes o necesarios.

$O$ dicho de otro modo, que al realizar un encuadramiento de una medida en una materia, ha de buscarse cuál es el fenómeno intervenido en la medida mediante un análisis de todos los aspectos de la misma (presupuesto, consecuencias, finalidades aparentes, etc.).

\subsubsection{Casos de interpretación fenomenológica}

Para concretar que sea este fenómeno social podemos acudir a las siguientes sentencias del TC.

La STC 143/1985 se discutía a quién correspondía realizar un acta de inspección al amparo de la Ley estatal sobre cuotas y 
distribución de pantallas cinematográficas. Según el TC, la finalidad de la Ley es asegurar «la proyección de películas españolas en determinados días para incrementar su número y calidad, a cuyo fin condiciona la obtención de licencias de doblaje de películas extranjeras, al rodaje, adquisición de derechos de explotación, estrenos o consecución de ciertos ingresos de películas españolas». Por ello concluye que "tratándose en este supuesto de la cinematografía considerada como una manifestación general de "espectáculo", que por regla general le resulta propia, al tender a la distracción, diversión o entretenimiento de las personas a través del fomento del cine español que se trata de proteger...ll la competencia corresponde a la CAC.

La STC 149/1985, en la que se discutía quién realizaba el control de taquilla cinematográfica, en relación con la gestión del Fondo de Protección Cinematográfica, el TC decide que no son aplicables las reglas relativas a los Medios de Comunicación Social, «así como su inclusión en la de cultura, porque la finalidad del Fondo no se dirige singular y exclusivamente a su fomento, sino a la cinematografía con carácter general, en su amplio espectro de entretenimiento o diversión, por lo que, igual que estimó la STC 143/1985, el título que en este supuesto actúa es el de espectáculos».

Finalmente, en la STC $106 / 1987$ se habían planteado tres cuestiones competenciales.

En la primera acción, se trataba de saber quién tenía que realizar una declaración de "especial interés» de las películas cinematográficas, medida ésta que suponía una excepción al régimen general de cuota de pantalla. EI TC analiza la legislación sobre una cuota de pantalla y termina concluyendo que se trata de una medida que "sacrifica un interés económico productivo en favor de un particular interés cultural, el cinematográfico, pues son los valores cinematográficos, como manifestación artística y espectáculo, los únicos que aquí se toman en consideración». En consecuencia, el título competencial aplicable es el de la cultura.

La segunda medida era la de calificar como especialmente adecuadas para la infancia a las películas, también a efectos de la cuota de pantalla. Para el Tribunal «resulta evidente que con esta medida, y con la consecuente calificación, se trata de promocionar la existencia de películas españolas que tengan como destinatarios cualificados a los menores». En consecuencia, también se integra en el título de la cultura. EI TC no aplicó aquí la materia «política infantil», probablemente porque ninguna de las partes hizo referencia a su eventual aplicación. 
Y la tercera se refiere a la concesión de licencias de doblaje de películas extranjeras, que está relacionada con las cuotas de distribución, en el sentido de que sólo se pueden exhibir películas extranjeras previa aquella licencia. EI TC analiza esta legislación y concluye que ula concesión de la licencia de doblaje es así la ejecución de una medida de protección de la industria cinematográfica española como tal», por lo que «los aspectos económicos se entrecruzan e incluso predominan sobre los específicamente culturales». El título aplicable es, por ello, el artículo 149.1 .13 sobre bases y coordinación de la planificación económica.

En conclusión, para el TC la cinematografía es, en términos generales, un fenómeno social que puede ser intervenido desde distintos puntos de vista. Cuando las medidas inciden sobre los aspectos culturales de la cinematografía, la materia es la cultura; pero si el fenómeno cinematográfico es considerado como un fenómeno de esparcimiento o diversión, entra en los espectáculos; y si lo que se mira es la producción de películas y su consideración como industria, entonces la materia es la «planificación económica».

\subsubsection{La característica más importante de la interpretación feno- menológica}

La característica más importante de la interpretación fenomenológica consiste en que intenta integrar la antinomia que se produce en las visiones puramente objetivas o teleológicas de las materias. Dicho en palabras del propio TC, las normas competenciales se refieren a uactividades concretas del poder respecto de determinados fines sociales" (STC 32/1981, f.j. 5).

La interpretación no es meramente objetiva, porque los fines que se pretenden en las medidas se tienen en cuenta, pero tampoco es puramente teleológica, porque se parte de los objetos regulados.

Esta integración de los elementos se produce porque los fines que se consideran en cada una de las medidas son inherentes o inmanentes. Es decir, que no se tienen en cuenta cuáles fueron los propósitos concretos de los poderes públicos al dictar las medidas, sino que sólo se tienen en cuenta los fines que racionalmente pueden justificar tales acciones. Así, una medida sanitaria siempre y necesariamente pretende salvaguardar, preservar o garantizar la salud; una medida de orden público, garantizar la seguridad ciudadana, etc. 


\section{LA INTERPRETACION SISTEMATICA DE LAS MATERIAS}

\subsection{INTRODUCCIÓN}

Asi pues, conforme a lo que hemos visto hasta aquí, el encuadramiento de una medida entre dos o más materias puede apoyarse, de una parte, en criterios extrínsecos al ordenamiento jurídico-constitucional, y, de otra parte, mediante una interpretación fenomenológica de las materias. Ahora bien, como el juicio del encuadramiento trata de fijar una correspondencia entre una norma o una acción y un conjunto hipotético de materias, y como éstas son numerosísimas, parece ineludible que sea necesario acudir, también, al criterio sistemático para resolver los problemas.

Las razones son evidentes, a la vista del volumen de voces existentes en nuestro bloque de la constitucionalidad, pero vale la pena recordarlas.

En efecto, si las materias pudieran tener varios significados jurídicos útiles, el edificio construido con las reglas competenciales se derrumbaría, puesto que las medidas podrían ser encuadradas entre dos o más materias, $y$, por io tanto, sería imposible identificar las reglas competenciales aplicables. Además, las reglas competenciales son normas jurídicas que, en el caso de conflicto, van a ser aplicadas e interpretadas de modo que se van a imponer a las partes. Si las materias pueden referirse a cualquier cosa o si las acciones discutidas pueden ser encuadradas en dos o más materias, cualquier imposición que se pueda hacer sobre su significado carece de la legitimidad jurídica y se convierte en arbitraria.

O dicho de otra manera, como todas la reglas de distribución de competencia deben tener una operatividad y funcionalidad jurídica, y como es ingente la cantidad de voces existentes, sólo mediante un análisis sistemático se puede, si quiera en primera hipótesis, identificar cuáles sean las materias aplicables.

Además, como conceptos jurídicos indeterminados que son, la precisión de su campo de juego se puede realizar no sólo de una manera intuitiva directa (zona de certidumbre), sino que también puede ser fijado en virtud de su contraste con otras materias (la zona negativa de certeza coincide con la zona de certeza positiva de otra materia). 
6.2 El MÉTOdO SISTEMÁtico Y LA CLÁUSULA de CIERRE DEL ARTÍCULO 149.3

¿Resulta posible, sin embargo, definir el campo propio de una materia sin pensar, inconscientemente, en otras materias? Es decir, que si el reparto de competencias fuese establecido en una sola norma que dijese que corresponde a $A$ la competencia exclusiva sobre $X, y$ corresponde a $B$ todo lo demás (es decir, no X). ¿Hay algún método posible capaz de definir qué es $X$ ?

La respuesta es aparentemente negativa, porque parece que nuestros conceptos o comprensiones sobre todas las cosas nacen precisamente del contraste, la distinción o los contrarios. La cuestión, sin embargo, es que la comprensión de lo que pertenece a cada materia no puede venir únicamente de la mano de los conceptos previstos en las normas competenciales, sino de una comprensión más amplia de la actividad de los poderes públicos.

En efecto, en la mayoría de los sistemas competenciales suele existir una cláusula que pone de manifiesto que no es posible definir cada materia en función de su contraste con otras. Es la cláusula de cierre del sistema que atribuye a un poder la competencia que no haya sido atribuida a otros poderes.

En nuestro sistema, la cláusula de cierre está contenida en el artículo 149.3 de la $C E$, establece que «la competencia sobre las materias que no se hayan asumido por los Estatutos de Autonomía corresponderá al Estado...». Dada la gran cantidad de voces que se han introducido en los EE AA (probablemente para hacer inaplicable esta cláusula), resulta difícil encontrar una materia que no haya sido prevista en el bloque de la constitucionalidad, ya que las acciones administrativas o las disposiciones tienen siempre un encaje más o menos ajustado a alguna de las voces existentes.

Aun asi, la existencia de una cláusula de cierre implica que, además de las materias mencionadas expresamente, existen actuaciones de los poderes públicos sobre asuntos, fenómenos u objetivos no mencionados en ellas, resultando así que el mero contraste no es suficiente para saber lo que está en aquéllas o lo que pertence a éstas.

Esto significa que la interpretación sistemática tiene un campo de juego importante, si bien no ha de olvidarse que, en último extremo, y como ya se ha adelantado, la decisión sobre cuál deba ser la materia aplicable depende de una concepción o comprensión del conjunto.

EI TC ha tenido que pronunicarse en tres ocasiones en relación con la eventual aplicación de la cláusula residual del artículo 149.3 de la Constitución. En dos de ellas (STC 71/1983 y 76/1984), la 
Abogacía del Estado sostenía que el Catálogo de Montes y la Cartografía eran materias no mencionadas expresamente en el EAC $y$, por lo tanto, que correspondía su ejercicio al Estado. EI TC declaró que el Catálogo de Montes era una facultad encuadrable en la materia de montes, que «a propósito de la actividad cartográfica, es patente, sin embargo, su carácter instrumental en relación con múltiples actividades de los particulares respecto a también numerosas actividades de las Administraciones públicas». Por ello concluye que «el silencio de la Constitución y del EA sobre ella se explica no como una reserva tácita y residual de competencia cartográfica estatal exclusiva en virtud del artículo $149.3 \mathrm{CE}$, sino como un también tácito reconocimiento de que no es la cartografía materia sobre la que sólo se pueda actuar en virtud de normas de atribución de competencias que, éstas sí, pueden pertenecer al Estatuto o a una Constitución».

En el tercer caso (STC 38/1982), sin embargo, hace uso del artículo 149.3 de la CE para considerar que la fijación de las precedencias relativas entre las autoridades autonómicas y estatales, al no estar prevista expresamente en el EAC, corresponde al E.

Conviene señalar que el Tribunal no estableció expresamente que habia realizado un análisis sistemático de todas las reglas competenciales existentes en el bloque de la constitucionalidad, pero se puede considerar como implícita.

\subsection{LA INTERPRETACIÓN SISTEMÁTICA EN EL PROBLEMA DEL ENCUA- DRAMIENTO}

La cuestión, de un modo general, no consiste en saber si existen relaciones intrínsecas entre las palabras y voces utilizadas en las normas jurídico-competenciales. Propiamente hablando, una vez que se ha descartado desconocer lo que contiene una materia, ese estudio es lógicamente imposible. Y como, además, las materias se refieren a puntos de vista de las intervenciones de los poderes públicos sobre fenómenos sociales, tampoco parece posible establecer, a priori, una tal relación.

Las conexiones entre las materias, en realidad, sólo se producen o se aprecian cuando una medida puede ser encuadrada en dos materias $y$, de acuerdo con las técnicas antedichas, no es posible llegar a una decisión clara y terminante. Es el caso, por ejemplo, de las medidas que pretenden informar a los consumidores y usuarios de los riesgos contra la salud que pueden producirse en los alimentos, que pueden pertenecer a la sanidad y a la defensa de los consumidores y usuarios, sin que podamos propiamente encontrar 
un criterio interpretativo directo para decidir cuál es la materia prevalente.

Por lo tanto, las relaciones entre las materias se nos muestran o manifiestan no de un modo directo, sino cuando estudiamos los encuadramientos de las medidas. Ahora bien, aunque una decisión adoptada en un caso concreto no permite realizar generalizaciones sobre una materia, pronto se advierte, a través sobre todo de esos casos límites, cuáles son las posibles relaciones que se pueden dar.

\subsection{LAS CLASES de RELACIONES QUE TEÓRICAMENTE PUEDEN DARSE ENTRE LAS MATERIAS}

Para un adecuado análisis de esta parte, sin embargo, parece imprescindible fijar, aunque sea arbitrario, una mínima terminología. Si descartamos los casos en los que nunca debería producirse un auténtico problema de encuadramiento, al menos desde una actitud mínimamente razonable (por ejemplo, entre las materias "ocio" y "espectáculos» y la materia «agricultura») parece que pueden advertirse tres clases de relaciones: de inclusión, de exclusión y de conexión.

\section{a) Relaciones de inclusión.}

Se dice que entre dos materias existe unas relaciones de inclusión, cuando una medida que se encuadra en una materia, parece que siempre y necesariamente, pertenece a otra materia. Sería el caso, por ejemplo de las medidas que recaen sobre los productos farmacéuticos que, de un modo general, parecen siempre estar relacionados con la salud $y$, por ende, en la materia sanidad. Igualmente sucedería con el caso de las materias "energía» e uinstalaciones de energía».

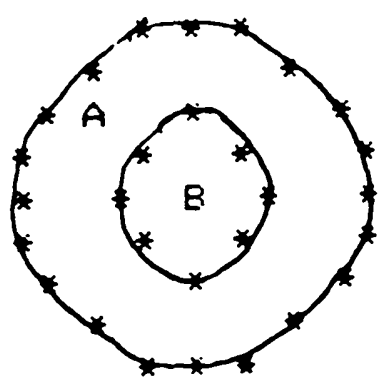

Relaciones de inclusión

Cuando se aprecia que existen estas relaciones, la consecuencia jurídica es que la medida ha de encuadrarse en la materia incluida, en perjuicio de la materia incluyente. La razón es de orden puramente lógico, pues, si se hace prevalecer a la materia genérica, la incluida deja de estar en juego y desaparece como criterio de distribución de competencias.

La existencia de estas relaciones de inclusión en nuestro ordenamiento competencial es muy abundante, porque hay muchas voces muy genéricas que parecen incluir a muchas otras voces más 
específicas. A título puramente expositivo de los casos que pueden darse nos podríamos encontrar con los siguientes:

1. La SANIDAD incluiría las materias «higiene», "sanidad interior», "sanidad exterior», "productos farmacéuticos» y «ordenación farmacéutica».

2. La materia CULTURA, a "Archivos», «bibliotecas», "conservatorios de música», "museos» y "patrimonio artístico, histórico, monumental y arqueológico».

3. La materia LEGISLACION CIVIL, a las de "formas del matrimonio» y "obligaciones contractuales».

4. La de REGIMEN JURIDICO DE LAS ADMINISTRACIONES PUBLICAS a las de "bienes de dominio público y patrimoniales», "contratos y concesiones administrativas», "expropiación forzosa», "procedimientos administrativos y económico-administrativos», "servidumbres públicas», "sistema de responsabilidad de la Administración».

5. EI MEDIO AMBIENTE puede incluir las materias "ecología» y "vertidos industriales y contaminantes en las aguas".

6. La materia TRANSITO Y TRANSPORTE AEREO incluye las de "aeropuertos», "aeropuertos deportivos», "helipuertos» y "control del espacio aéreon.

7. PUERTOS es una voz general que incluye a upuertos deportivos», "puertos de refugio" y "puertos no comerciales».

8. EI COMERCIO EXTERIOR incluye las «Ferias Internacionales», mientras que el COMERCIO INTERIOR a las «ferias y mercados interiores".

9. La voz MEDIOS DE COMUNICACION SOCIAL incluye las materias «prensa, radio y televisión».

10. La AGRICULTURA puede incluir la voz "cámaras agrarias»; la de GANADERIA a las de "pastos» y "vías pecuarias»; la de SECTOR PESQUERO a las de "pesca marítima», "pesca en aguas interiores», "cofradía de pescadores» y, quizá, "acuicultura».

\section{b) Relaciones de exclusión.}

Por el contrario, se dice que entre dos materias se produce una relación de exclusión, cuando una medida que pertenece a una materia, parece que siempre $y$ necesariamente, queda excluida de otra materia. Sería el caso de las relaciones entre la "ganadería» y la uagricultura». Ambas pueden incluir las medidas rela-

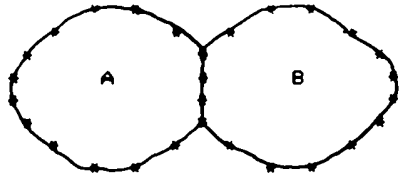

Relaciones de exclusión: lo que pertenece a $A$ no puede pertenecer a $B$ 
cionadas con la producción de bienes, pero éstos no pueden ser simultáneamente vegetales $o$ animales, resultando asi, que son excluyentes entre sí. Este ejemplo no es baladi, en absoluto, ya que existe un conflicto planteado ante el TC en el que uno de los aspectos que las partes consideran importantes es si el coral es un animal o un vegetal, lo que hace que pueda encuadrarse una medida que regula la pesca del coral en las materias upesca marítima» o la "acuicultura».

En este caso, la consecuencia jurídica es que si se decide que una clase de medidas pertenece a una materia, todas las demás que sean semejantes deberán también incluirse en ella, no pudiendo nunca entrar en juego la otra materia excluida.

También en nuestro sistema competencial pueden encontrarse casos muy claros de materias que son excluyentes entre sí. Utilizando ahora sólo voces muy generales o amplias, se pueden indicar los siguientes:

1. En el ámbito jurídico, deben considerarse excluyentes las materia exterior o internacional es también excluyente, como ocurre con la "sanidad interior» y la "sanidad exterior»; el "comercio interior» y el "comercio exterior»; las "ferias interiores" y las "ferias internacionales».

2. En el ámbito económico, los distintos sectores productivos serían excluyentes entre sí, por ejemplo, «industria», "energía», "ganadería», "agricultura», "turismo».

3. La distinción de una materia interior o nacional y una materia exterior o internacional es también excluyente, como ocurre con la "sanidad interior» y la "sanidad exterior»; el "comercio interior" y el "comercio exterior»; las "ferias interiores" y las "ferias internacionales».

Un caso peculiar de exclusión entre dos materias se encuentra en la STC 71/1982 en la que se trataba de saber qué era la "ordenación farmacéutica» y en la cual su contraste con la materia de "productos farmacéuticos» le permite determinar su zona de certidumbre negativa:

«Si la edición de normas jurídicas que disciplinen el régimen de los productos farmacéuticos compete al Estado, y en esta área el PV es titular de una competencia ejecutiva, pero no normativa, habrá que entender que en la regla del artículo 10.15 (ordenación farmacéutica) no se asume ninguna competencia normativa de ordenación de los productos farmacéuticos.» 


\section{c) Relaciones de conexión.}

Finalmente, las relaciones son propiamente de conexión cuando se percibe que entre dos materias existe una zona de confluencia o contacto, en la cual se encuentran medidas que pueden pertenecer a ambas materias, mientras que existen zonas independientes, en las que no parece existir esa posibilidad de confluencia, sería el caso, por ejemplo, de las

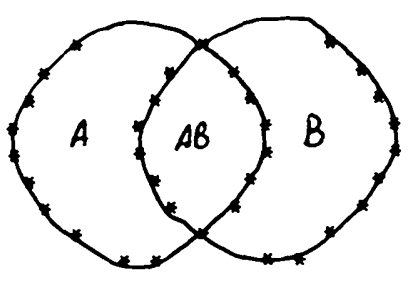

Relaciones de conexión materias "defensa del consumidor y del usuario» y "defensa de la competencia», en las que se pueden identificar medidas que pertenecen únicamente a una de ellas, pero también hay casos en los que parece darse medidas encuadrables en las dos.

Como las relaciones de conexión son las más frecuentes, merece que les dediquemos un poco más de atención. La primera observación que cabe hacer es que la interpretación fenomenológica del TC tiende, casi necesariamente, a producir este tipo de relaciones, pues como se adelantó, esta interpretación tiende a considerar que una materia se refiere a un punto de vista de intervenir un fenómeno por los poderes públicos. De aquí que las materias "cultura», "sanidad», "actividad económica», «industria» y otras más o menos genéricas se convierten en materias conexas, per definitionem, pues es difícil encontrar un fenómeno social en el que no exista un aspecto o punto de vista económico, cultural, sanitario, etc.

Las relaciones de conexión parece que se dan de un modo natural entre las materias que se refieren a sujetos $u$ objetos $y$ materias que se refieren a sectores o actividades.

Materias que se refieren a objetos son, por ejemplo, las que mencionan cosas muebles (por ejemplo, las aguas) 0 inmuebles (instalaciones eléctricas). Entre las materias subjetivas, en el sentido amplio, se pueden encontrar, a su vez, a personas individuales físicas (funcionarios públicos) o jurídicas (fundaciones), grupos de personas (la tercera edad) y organismos o instituciones de todo tipo, públicos (instituciones penitenciarias), semipúblicos (colegios profesionales) y privados (banca).

$Y$, por otra parte, existen voces que se refieren a todas clases de sectores: económicos (la industria), sociales (la sanidad), culturales (la enseñanza) o jurídicos (el derecho civil); o de actividades también de todo tipo: económicas (el crédito), sociales (la asistencia social), culturales (el ocio), políticas (la legislación electoral). 
Teniendo en cuenta esto, es claro que una materia que se refiere a una actividad puede estar conectada con una materia subjetiva. Propiamente hablando, una vez que se ha advertido que nos encontramos en una zona de confluencia, la decisión jurídica debería quedar aún pendiente, porque no hay criterio válido que permita decidirse por una de las materias, en disfavor de la otra, salvo el de que cada materia debe permanecer en juego.

Este sería el caso de las Sentencias del TC 48/1988 y /1988, sobre las leyes autonómicas y estatales reguladoras de las Cajas de Ahorro, en las que se trataba de deslindar el juego recíproco de dos rítulos: Uno subjetivo, "Cajas de Ahorro», y otro de actividad, "la ordenación del crédito». El Tribunal Constitucional admite que el título subjerivo tiene un cierto núcleo de certeza referido a la organización y funcionamiento interno de estas sociedades, mientras que el título de la actividad se referiría a las cuestiones externas. Sin embargo, sostiene que hay un elemento de confluencia que difumina y complica estas distinciones: El hecho de que la organización $y$ los aspectos internos de estas sociedades pueden suponer incidir o afectar a su actividad económica y crediticia, por lo que en esa zona de incertidumbre o penumbra hay que estudiar, caso a caso, si las normas estatales que regulan la organización y funcionamiento internos de las Cajas de Ahorro deben considerarse como básicas o como supletorias.

\subsection{LA UTILIZACIÓN DE LA INTERPRETACIÓN SISTEMÁTICA POR EL TC}

Si se afirmase que el TC no hace uso de una interpretación sistemática de los preceptos constitucionales, no se estaría haciendo justicia a su modo de actuar, puesto que, al contrario, es éste, con casi toda probabilidad, uno de los métodos más importantes que ha seguido para adoptar sus decisiones. Asi, por ejemplo, la existencia de un orden económico general, que es un principio que no está constitucionalizado expresamente, es deducido por el TC, de la interpretación sistemática de diversos artículos, «tales como el 128, entendido en su totalidad; el 131.1. el 139.2 y el 138.1 , entre otros».

Igualmente, cuando se ha tratado de resolver conflictos de competencias, el método sistemático le ha permitido adoptar principios tal y como queda patente en la STC 32/1983 (Coordinación sanitaria), en la que el Tribunal, después de recordar lo dispuesto en diversos artículos de la Constitución, tales como el 43 , el 51 , el 139.2 y el 149.1.1, dice que: 
"De la interpretación sistemática de todos estos preceptos se infiere la exigencia constitucional de que exista un sistema normativo de la sanidad nacional, puesto que los derechos que la Constitución reconoce en los artículos 43 y 51 (...) pertenecen a todos los españoles y a todos se les garantiza por el Estado la igualdad en las condiciones básicas para el ejercicio de los mismos.»

Esto sentado, cuando el problema competencial ha consistido en encuadrar una acción entre dos o más materias conexas entre sí, el TC ha tenido en cuenta también que hay voces sobre las materias que son más específicas que otras, por lo que aquéllas deben prevalecer. Conviene señalar, sin embargo, que el TC ha aplicado este principio a dos tipos de relaciones diferentes: Las de inclusión y las de conexión.

\section{a) Aplicación en las relaciones de inclusión.}

Un caso de aplicación de esta regla en relaciones de inclusión es el previsto en la STC 24/1985. La cuestión era saber si una autorización para instalar una unidad destinada a la obtención de productos petrolíferos ligeros a partir de medios y pesados debía encuadrarse en el ámbito de la energía o en el de la industria. EI TC rechazó además la pretensión de una de las partes, según la cual las reglas específicas debian ser interpretadas restrictivamente:

«Para ello dicha representación (del G. V.) califica el apartado 30 de "régimen jurídico general" de las competencias en materia de industria, contraponiéndolo a lo que a su juicio es el "régimen jurídico especial" en materia de energía del apartado 11, y llegando por este camino a la conclusión de que, en cuanto norma especial, e incluso "excepcional", el apartado 11 del artículo 10 ha de ser objeto de una interpretación restrictiva. Ahora bien, el carácter de norma especial de dicho apartado, frente al de norma general del apartado 30 del artículo 10, no autoriza a ver en ella una norma "excepcional" , ni a someterla a una interpretación restrictiva, pues tal carácter viene a significar aqui que en materia específica de la energía las competencias asumidas por la CA son precisamente las previstas en el apartado $.11 \mathrm{y}$ no las contempladas para el sector industrial en general por el artículo 30.» (f.j. 4.) 
b) Relaciones de conexión.

En los demás casos en los que ha aplicado la regla las relaciones eran de conexión entre dos materias, la sanidad y la defensa del consumidor. Así, en la STC 71/1982 se declara que: «El carácter específico de la sanidad, respecto del plural de la defensa del consumidor, determina que la inclusión en regla de más amplio alcance debe ceder ante la regla más especial y, por tanto, la de preferente aplicación debe ser aquí la de sanidad.»

Esta misma doctrina se sigue en las Sentencias del TC 66/1988 y $80 / 1988$, en las que el problema es encuadrar una medida en las materias "sanidad" o «igualdad de los derechos y deberes», concluyendo el TC que «también aquí el título más específico ha de prevalecer frente al más genérico» (f.j. 3 STC 80/1988).

Sin embargo, es forzoso señalar que, a nuestro juicio, no es lícito decir que la materia sanidad es más especial que la materia defensa del consumidor, pues, aunque es cierto que algunas medidas pretenden, simultáneamente, defender la salud y a los consumidores, esto no ocurre siempre, de modo que entre ambas materias lo que hay es relaciones de conexión.

Por otra parte, si una medida puede ser encuadrada en la sanidad y en la defensa del consumidor, no hay razón alguna que permita considerar que deba prevalecer la sanidad, por el mero hecho de que sea una materia más específica, pues, de seguir este razonamiento, la que quedaría fuera de juego siempre sería la otra, la defensa del consumidor, que coexiste y está conectada con multitud de otras materias, todas las cuales son también más específicas (por ejemplo, vivienda, agricultura, ganadería, industria).

Así lo ha visto el propio TC al referirse al juego de la materia "fomento de la investigación científica y técnica», señalando que:

"Aunque en otros muchos casos hemos recurrido para resolver controversias de este género, al procedimiento de determinar cuál de los dos títulos competenciales había de ser considerado prevalente..., no hay necesidad de acudir aquí a un procedimiento semejante. Uno de los títulos en presencia (el de fomento de investigación científica $y$ técnica) es, como determinado en razón de un fin, susceptible de ser utilizado respecto de cualquier género de materias con independencia de cuál sea el titular de la competencia para la ordenación de éstas. De otro modo, en efecto, por la simple sustracción de las materias sobre las que las CC AA han adquirido competencia el título competencial que reserva al Estado como competencia exclusiva el fomento de la investigación científica y técnica quedaría, 
como dice el Abogado del Estado, vacío de todo contenido propio....

Quizás por esta razón el TC en las referidas sentencias 66/1980 y $80 / 1988$, en las que se planteaba un conflicto entre dos normas, una de las cuales pertenecía a la sanidad, mientras que la otra pertenecía a la defensa del consumidor, el TC, en lugar de apelar al criterio de la especialidad, valora los más altos bienes jurídicos en juego de la sanidad, señalando que:

«... la competencia en materia de defensa del consumidor y del usuario que ostenta la CA de Galicia no excluye la que al Estado confiere el artículo 149.1.16 de la Constitución (sanidad) para dictar normas que, por su finalidad de aseguramiento uniforme de las condiciones de igualdad en la protección de la salud de todos los consumidores potenciales de cualquier clase de productos, y especialmente de los alimenticios, constituyen reglas básicas de apicación general, delimitadoras de aquella competencia autonómica...» (f. j. 4).

Todavía más, si la máxima «la regla especial prevalece sobre la regla general» hubiese sido aplicada con rigor en los casos de relaciones de conexión entre materias, significaría la aplicación restringida de los títulos más genéricos o generales, tales como el desarrollo o la ordenación económica, lo cual, sin embargo, no sólo no ha sido tenido en cuenta por el propio TC, sino que ha declarado que las competencias específicas de las Comunidades Autónomas están limitadas por las competencias el Estado.

ANEXO

LISTA DE MATERIAS CONTENIDAS EN LA CE Y EN EL EAPV ORDENADAS POR SECTORES

\begin{tabular}{c|l|c}
\hline Número & \multicolumn{1}{|c|}{ Voz } & \multicolumn{1}{c}{ Sector } \\
\hline 1 & $\begin{array}{l}\text { Asociaciones doc. cul. art. ben. asis. y simila- } \\
\text { res. } \\
2\end{array}$ & Sanidad exterior. \\
3 & $\begin{array}{l}\text { Ordenación farmacéutica. } \\
\text { Productos farmacéuticos. } \\
4\end{array}$ & \\
Higiene. \\
Sanidad interior. \\
7
\end{tabular}




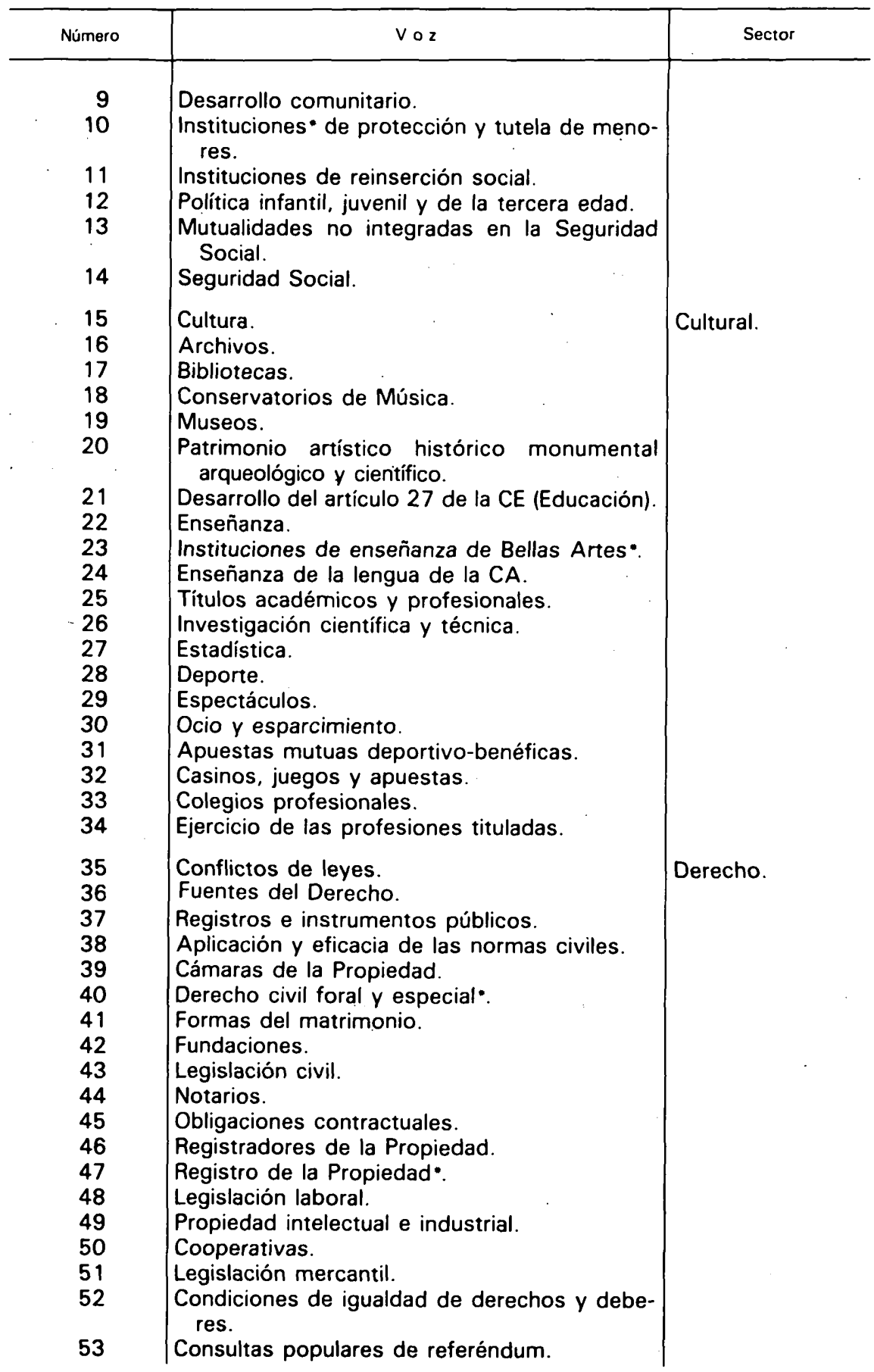




\begin{tabular}{|c|c|c|}
\hline Número & Voz & Sector \\
\hline $\begin{array}{l}54 \\
55 \\
56 \\
57 \\
58\end{array}$ & $\begin{array}{l}\text { Nacionalidad, extranjeria, derecho de asilo. } \\
\text { Bienes de dominio público y patrimoniales. } \\
\text { Contratos y concesiones administrativas. } \\
\text { Demarcaciones territoriales municipales. } \\
\text { Estatuto de los funcionarios de la Administra- } \\
\text { ción Local. }\end{array}$ & \\
\hline $\begin{array}{l}61 \\
62\end{array}$ & $\begin{array}{l}\text { Hacienda general. } \\
\text { Procedimientos administrativos y económico- } \\
\text { administrativo. }\end{array}$ & \\
\hline $\begin{array}{l}63 \\
64\end{array}$ & $\begin{array}{l}\text { Régimen estatutario de los funcionarios. } \\
\text { Régimen jurídico de las Administraciones públi- } \\
\text { cas. }\end{array}$ & \\
\hline $\begin{array}{l}65 \\
66 \\
67\end{array}$ & $\begin{array}{l}\text { Régimen local. } \\
\text { Servidumbres públicas. } \\
\text { Sistema de responsabilidad de la Administra- } \\
\text { ción. }\end{array}$ & \\
\hline $\begin{array}{l}68 \\
69 \\
70 \\
71 \\
72 \\
73 \\
74 \\
75 \\
76\end{array}$ & $\begin{array}{l}\text { Procedimiento administrativo común. } \\
\text { Administración de Justicia*. } \\
\text { Defensor del Pueblo. } \\
\text { Instituciones de autogobierno*. } \\
\text { Legislación electoral interior. } \\
\text { Instituciones penitenciarias. } \\
\text { Legislación penal. } \\
\text { Legislación penitenciaria. } \\
\text { Legislación procesal. }\end{array}$ & \\
\hline $\begin{array}{l}77 \\
78 \\
79 \\
80\end{array}$ & $\begin{array}{l}\text { Agentes de Cambio y Bolsa. } \\
\text { Bolsas de Comercio. } \\
\text { Cámaras de Comercio, Industria y Navegación. } \\
\text { Centros de Contratación Comercial y de Mer- } \\
\text { cancias. }\end{array}$ & Economía. \\
\hline $\begin{array}{l}81 \\
82 \\
83 \\
84 \\
85 \\
86 \\
87 \\
88 \\
89\end{array}$ & $\begin{array}{l}\text { Comercio exterior. } \\
\text { Comercio interior. } \\
\text { Corredores de Comercio. } \\
\text { Defensa del consumidor y del usuario. } \\
\text { Denominaciones de origen. } \\
\text { Ferias internacionales. } \\
\text { Ferias y mercados interiores. } \\
\text { Régimen aduanero y arancelario. } \\
\text { Cables aéreos, submarinos y radiocomunica- } \\
\text { ción. }\end{array}$ & . \\
\hline $\begin{array}{l}90 \\
91 \\
92 \\
93 \\
94 \\
95 \\
96 \\
97\end{array}$ & $\begin{array}{l}\text { Correos y telecomunicaciones. } \\
\text { Medios de Comunicación Social. } \\
\text { Prensa, Radio y Televisión. } \\
\text { Publicidad. } \\
\text { Aguas minerales, termales y subterráneas. } \\
\text { Aprovechamientos hidráulicos. } \\
\text { Canales y regadios. } \\
\text { Agricultura. }\end{array}$ & \\
\hline
\end{tabular}




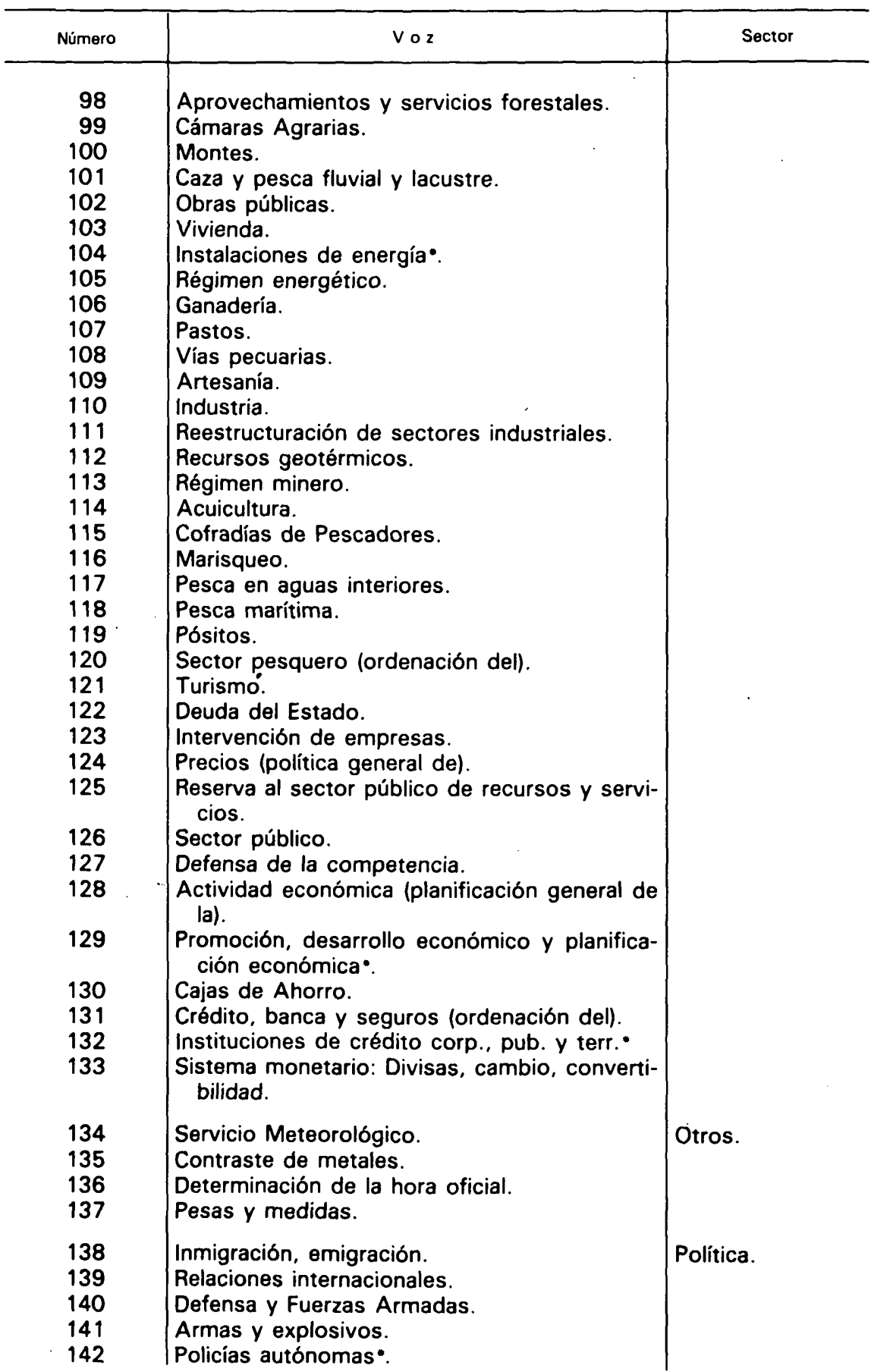




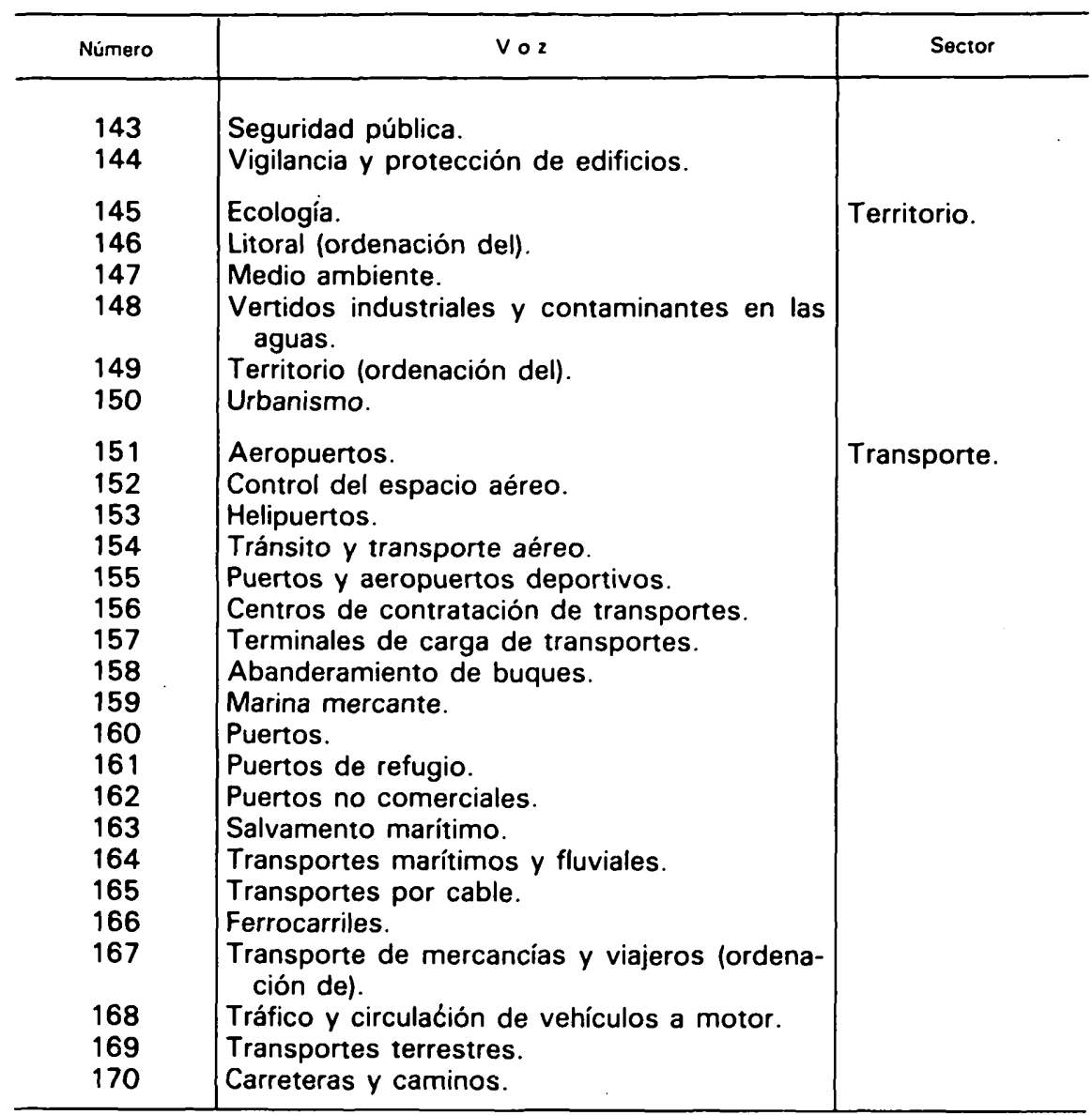


REALA-1988, núm. 238. SAMANIEGO, GONZALO. LOS PROBLEMAS DE INTERPRETACION Y APLI... 
REALA-1988, núm. 238. SAMANIEGO, GONZALO. LOS PROBLEMAS DE INTERPRETACION Y APLI...

II. CRONICAS

REALA-1988, núm. 238. SAMANIEGO, GONZALO. LOS PROBLEMAS DE INTERPRETACION Y APLI... 
REALA-1988, núm. 238. SAMANIEGO, GONZALO. LOS PROBLEMAS DE INTERPRETACION Y APLI...

REALA-1988, núm. 238. SAMANIEGO, GONZALO. LOS PROBLEMAS DE INTERPRETACION Y APLI... 